\title{
Research trends in combinatorial optimization
}

\author{
Jann Michael Weinand ${ }^{\mathrm{a}, *}$ (iD), Kenneth Sörensen ${ }^{\mathrm{b}}$ (D), Pablo San Segundo ${ }^{\mathrm{c}}$, \\ Max Kleinebrahm ${ }^{\mathrm{a}}$ and Russell McKenna ${ }^{\mathrm{d}}$ \\ ${ }^{a}$ Chair of Energy Economics, Institute for Industrial Production, Karlsruhe Institute of Technology, Karlsruhe 76131, \\ Germany \\ ${ }^{\mathrm{b}}$ Department of Engineering Management, University of Antwerp, Antwerp 2000, Belgium \\ ${ }^{\mathrm{c}}$ Centre for Automation and Robotics, Universidad Politécnica de Madrid, Madrid 28040, Spain \\ ${ }^{\mathrm{d}}$ Chair of Energy Transition, School of Engineering, University of Aberdeen, Aberdeen AB24 3FX, Scotland \\ E-mail: jann.weinand@kit.edu [Weinand]; kenneth.sorensen@uantwerpen.be [Sörensen]; pablo.sansegundo@upm.es \\ [San Segundo]; max.kleinebrahm@kit.edu [Kleinebrahm]; russell.mckenna@abdn.ac.uk [McKenna]
}

Received 2 December 2020; received in revised form 3 March 2021; accepted 12 May 2021

\begin{abstract}
Real-world problems are becoming highly complex and therefore have to be solved with combinatorial optimization (CO) techniques. Motivated by the strong increase in publications on CO, 8393 articles from this research field are subjected to a bibliometric analysis. The corpus of literature is examined using mathematical methods and a novel algorithm for keyword analysis. In addition to the most relevant countries, organizations, and authors as well as their collaborations, the most pertinent $\mathrm{CO}$ problems, solution methods, and application areas are presented. Publications on $\mathrm{CO}$ focus mainly on the development or enhancement of metaheuristics like genetic algorithms. The increasingly problem-oriented studies deal particularly with real-world applications within the energy sector, production sector, or data management, which are of increasing relevance due to various global developments. The demonstration of global research trends in $\mathrm{CO}$ can support researchers in identifying the relevant issues regarding this expanding and transforming research area.
\end{abstract}

Keywords: combinatorial optimization; bibliometric analysis; metaheuristics; genetic algorithms; exact algorithms; OR in energy

\section{Introduction}

Combinatorial optimization (CO) has always been of great interest in the scientific community (Cacchiani et al., 2018). In CO, problems are investigated that are characterized by a finite number of possible solutions (Bjorndal et al., 1995). While the discrete nature of these problems allows

${ }^{*}$ Corresponding author.

(C) 2021 The Authors.

International Transactions in Operational Research published by John Wiley \& Sons Ltd on behalf of International Federation of Operational Research Societies

This is an open access article under the terms of the Creative Commons Attribution License, which permits use, distribution and reproduction in any medium, provided the original work is properly cited. 
them to be solved in finite time by listing candidate solutions one by one and selecting the optimal solution, the number of such candidates typically grows rapidly with the input size, making many practical optimization problems insoluble for simple enumeration schemes (Cook, 2019). Researchers in $\mathrm{CO}$ explore the structural features of the problems and use these features to develop both precise and approximate general solution techniques. Usually, these $\mathrm{CO}$ problems are categorized based on their computational complexity. However, this worst-case evaluation does not always reflect the actual computational feasibility; the actual difficulty of the problems drives the development of solution approaches (Bjorndal et al., 1995). Through the development of effective methods and innovative approaches, as well as advances in software and hardware technology, hard real-world problems can already be solved more efficiently (Pardalos et al., 2013; Cacchiani et al., 2018). At the same time, new challenges are emerging, such as the consideration of uncertain conditions, the combination of hard problems, and the solving of problems in real time (Cacchiani et al., 2018).

In this context, the number of publications on $\mathrm{CO}$ problems has increased significantly in recent years (8393 in 2019, cf. Section 3.1), with over 150 reviews on the subject. However, these reviews cover only certain aspects of $\mathrm{CO}$ : for example, there are many reviews on specific $\mathrm{CO}$ problems such as the quadratic assignment problem (Loiola et al., 2007), the dynamic (Pillac et al., 2013) and the multiobjective (Jozefowiez et al., 2008) vehicle routing problem, the location-routing problem (Nagy and Salhi, 2007; Prodhon and Prins, 2014), or the minimum spanning tree problem (Pop, 2020). Furthermore, many studies review metaheuristics in CO in general (Blum and Roli, 2003; Gendreau and Potvin, 2005) or in comparison to each other regarding a specific problem (e.g., traveling salesman problem, TSP; Halim and Ismail, 2019). In addition, particular metaheuristics like ant colony optimization (Blum, 2005), other solution algorithms like Benders decomposition (Rahmaniani et al., 2017) as well as real-world applications of CO (e.g., sustainable supply chain network design; Eskandarpour et al., 2015) are reviewed.

Hence, a review of this growing body of literature, which thereby shows an overall picture of the $\mathrm{CO}$ research area, should be beneficial for $\mathrm{CO}$ researchers to understand and identify research and trends in $\mathrm{CO}$ in its entirety. For this purpose, different quantitative and qualitative approaches are employed to understand and organize the findings of existing studies. A bibliometric analysis is one of these approaches and has the potential to provide a systematic, reproducible, and transparent review process based on statistical measurements of research activities and researchers (Aria and Cuccurullo, 2017). This type of review can be classified as more objective and reliable than traditional review methods. Through a structured analysis of the extensive information on $\mathrm{CO}$, the bibliometric review in this study can therefore achieve the following objectives (Aria and Cuccurullo, 2017): infer trends over time; show themes researched; identify shifts in the boundaries of the disciplines; detect the most prolific authors, organizations, and countries; and present an overview of the extant research. However, this paper should not be read as a complete and exhaustive list of all contributions in the field of $\mathrm{CO}$, but rather as an insight into the current research focus and some of the most important challenges in the field, with the bibliometric study (including all of its limitations) used as a tool to highlight them.

These objectives are achieved with the present review study on CO. For this purpose, the paper is structured as follows. Section 2 describes the main methodological aspects of this study. Subsequently, the results and discussion of the bibliometric analysis are presented in Sections 3 and 4, respectively. Finally, Section 5 gives a summary and provides some conclusions.

(C) 2021 The Authors.

International Transactions in Operational Research published by John Wiley \& Sons Ltd on behalf of International Federation of Operational Research Societies 
Table 1

Search queries and resulting number of articles in the literature database Web of Science

\begin{tabular}{|c|c|c|c|}
\hline Search name & Search query & Date & $\begin{array}{l}\text { Number of } \\
\text { studies }\end{array}$ \\
\hline $\begin{array}{l}\text { Optimization in } \\
\text { general }\end{array}$ & $\begin{array}{l}\text { (TS = "optimi*") AND } \\
\text { LANGUAGE: (English) AND } \\
\text { DOCUMENT TYPES: (Article) } \\
\text { Timespan: 1990-2019. Indexes: } \\
\text { SCI-EXPANDED, SSCI. }\end{array}$ & 23 March 2020 & $1,086,301$ \\
\hline Initial search & $\begin{array}{l}\text { (TS }=\text { "combinatorial optimi*”) } \\
\text { Timespan: 1990-2019. Indexes: } \\
\text { SCI-EXPANDED, SSCI }\end{array}$ & 23 March 2020 & 8769 \\
\hline Adjusted search & $\begin{array}{l}\text { (TS = "combinatorial optimi*") } \\
\text { AND LANGUAGE: (English) } \\
\text { AND DOCUMENT TYPES: } \\
\text { (Article) } \\
\text { Indexes = SCI-EXPANDED, SSCI } \\
\text { Timespan = 1990-2019 }\end{array}$ & 23 March 2020 & 8393 \\
\hline
\end{tabular}

\section{Methodology}

The research object of bibliometric analyses is a document system as well as the bibliometric characteristics of the individual documents. Thereby, the structure, features, and patterns of the underlying science are examined using mathematical and statistical methods (Weinand, 2020). The literature database Web of Science ${ }^{1}$ and the web interface biblioshiny of the R-tool bibliometrix (Aria and Cuccurullo, 2017) are used to investigate the literature on CO. In Web of Science, the adjusted search query in Table 1 is used. In addition to the bibliometric analysis tool bibliometrix (Section 2.1), the statistical indicators $h$-, $g$-, and $m$-index (Section 2.2), an approach to measure trends (Section 2.3) and an algorithm for keyword and author analyses (Section 2.4) are explained in the following.

\subsection{R-tool bibliometrix}

The main part of the present analysis is based on the Web of Science analyzing tool and evaluations based on a newly developed algorithm (cf. Section 2.4). In addition, the R-tool bibliometrix is applied for the examination of the corpus of literature. Bibliometrix is an open-source tool for conducting comprehensive scientific mapping analyses. This tool has already been used in many bibliometric analyses. Due to its implementation in $\mathrm{R}$, the package is flexible and facilitates integration with other statistical or graphical packages (Aria and Cuccurullo, 2017). One example for which bibliometrix has been used is determining the number of country collaborations (cf. Table 3 ).

${ }^{1}$ See http://apps.webofknowledge.com/WOS_GeneralSearch_input.do?product=WOS\&search_mode=GeneralSearch $\& \mathrm{SID}=\mathrm{D} 3 \mathrm{JAVHgH6kUCRXvVCDb} \&$ preferencesSaved $=$. 
Table 2

Arrow icons showing the trend of the increase in publications, using an example with a maximum average annual percentage increase in publications of $100 \%$

\begin{tabular}{ll}
\hline $\begin{array}{l}\text { Interval of average annual percentage } \\
\text { increase in publications }(\%)\end{array}$ & Arrow icon \\
\hline$[0 ; 20]$ & $\rightarrow$ \\
$(20 ; 40]$ & $\nearrow$ \\
$(40 ; 60]$ & $\uparrow$ \\
$(60 ; 80]$ & $\uparrow \uparrow$ \\
$(80 ; 100]$ & $\uparrow \uparrow \uparrow$ \\
\hline
\end{tabular}

\subsection{Measures of influence: $\mathrm{h}$-index, $\mathrm{m}$-index, and $\mathrm{g}$-index}

A variety of indices have been introduced in the past to measure research impact. The $h$-index was introduced to facilitate quantifying the cumulative impact and relevance of an individual's scientific output (Hirsch, 2005). Thereby an individual is associated to publications and can therefore be an author (cf. Table A1), country (cf. Table 3), organization (cf. Table 4), or source (cf. Table 5). The $h$ index reflects the number of $h$ papers of an individual that have been cited at least $h$ times. Together with the $h$-index, Hirsch (2005) also provided the $m$-index, which reflects the time period since the first publication of an individual by dividing the $h$-index by the number of years of scientific activity. Hirsch (2005) also classifies different values of the $m$-index with $m=1$ being a "successful scientist", $m=2$ being an "outstanding scientist," and $m=3$ being a "truly unique individual." The $g$-index was introduced by Egghe (2006) as an alternative of the $h$-index. It represents the unique largest number of the top $g$ most cited articles, which together received at least $g^{2}$ citations. This index therefore gives a higher weighting to highly cited articles than the $h$-index. In the present study, however, these indices cannot be used to evaluate a single individual's scientific activity but only for comparison with each other. This is because the publications on CO represent only a subset of an individual's total publications. As a result, for example, in relation to this subset the $m$-index is below 1 for all authors (cf. Table A1), whereas in relation to all publications by these authors could be well above 1 .

\subsection{Measuring trends}

Important for the analysis of a research field are not only static measures but also the development of these indicators over time. Therefore, in some tables in Section 3, trends concerning the number of publications are indicated by arrow icons. To estimate the trends, publications from 2015 to 2019 are considered. The percentage increase in the number of publications per year is calculated, followed by the average from 2015 to 2019 . The highest average value is then divided into five equal ranges. An example is used to show this measurement: it is assumed that the highest average annual percentage increase in publications of 20 countries between 2015 and 2019 is 100. In this case, an indication of the trend by means of arrow icons for different intervals as shown in Table 2 would be applied. 
(a)

\begin{tabular}{|c|c|c|c|c|c|c|c|c|c|c|c|c|c|c|}
\hline & & $\mathbf{C}$ & $\mathbf{O}$ & $\mathbf{M}$ & $\mathbf{B}$ & $\mathbf{I}$ & $\mathbf{N}$ & $\mathbf{A}$ & $\mathbf{T}$ & $\mathbf{O}$ & $\mathbf{R}$ & $\mathbf{I}$ & $\mathbf{A}$ & $\mathbf{L}$ \\
\hline & 0 & 1 & 2 & 3 & 4 & 5 & 6 & 7 & 8 & 9 & 10 & 11 & 12 & 13 \\
\hline $\mathbf{C}$ & 1 & 0 & 1 & 2 & 3 & 4 & 5 & 6 & 7 & 8 & 9 & 10 & 11 & 12 \\
\hline $\mathbf{O}$ & 2 & 1 & 0 & 1 & 2 & 3 & 4 & 5 & 6 & 7 & 8 & 9 & 10 & 11 \\
\hline $\mathbf{M}$ & 3 & 2 & 1 & 0 & 1 & 2 & 3 & 4 & 5 & 6 & 7 & 8 & 9 & 10 \\
\hline $\mathbf{P}$ & 4 & 3 & 2 & 1 & 1 & 2 & 3 & 4 & 5 & 6 & 7 & 8 & 9 & 10 \\
\hline $\mathbf{U}$ & 5 & 4 & 3 & 2 & 2 & 2 & 3 & 4 & 5 & 6 & 7 & 8 & 9 & 10 \\
\hline $\mathbf{T}$ & 6 & 5 & 4 & 3 & 3 & 3 & 3 & 4 & 4 & 5 & 6 & 7 & 8 & 9 \\
\hline $\mathbf{E}$ & 7 & 6 & 5 & 4 & 4 & 4 & 4 & 4 & 5 & 5 & 6 & 7 & 8 & 9 \\
\hline
\end{tabular}

(b)

\begin{tabular}{|c|c|c|c|c|c|c|c|c|c|c|c|c|c|c|}
\hline & & $\mathbf{C}$ & $\mathbf{O}$ & $\mathbf{M}$ & $\mathbf{B}$ & $\mathbf{I}$ & $\mathbf{N}$ & $\mathbf{A}$ & $\mathbf{T}$ & $\mathbf{O}$ & $\mathbf{R}$ & $\mathbf{I}$ & $\mathbf{A}$ & $\mathbf{L}$ \\
\hline & 0 & 1 & 2 & 3 & 4 & 5 & 6 & 7 & 8 & 9 & 10 & 11 & 12 & 13 \\
\hline $\mathbf{C}$ & 1 & 0 & 1 & 2 & 3 & 4 & 5 & 6 & 7 & 8 & 9 & 10 & 11 & 12 \\
\hline $\mathbf{O}$ & 2 & 1 & 0 & 1 & 2 & 3 & 4 & 5 & 6 & 7 & 8 & 9 & 10 & 11 \\
\hline $\mathbf{M}$ & 3 & 2 & 1 & 0 & 1 & 2 & 3 & 4 & 5 & 6 & 7 & 8 & 9 & 10 \\
\hline $\mathbf{P}$ & 4 & 3 & 2 & 1 & 1 & 2 & 3 & 4 & 5 & 6 & 7 & 8 & 9 & 10 \\
\hline $\mathbf{U}$ & 5 & 4 & 3 & 2 & 2 & 2 & 3 & 4 & 5 & 6 & 7 & 8 & 9 & 10 \\
\hline $\mathbf{T}$ & 6 & 5 & 4 & 3 & 3 & 3 & 3 & 4 & 4 & 5 & 6 & 7 & 8 & 9 \\
\hline $\mathbf{A}$ & 7 & 6 & 5 & 4 & 4 & 4 & 4 & 3 & 4 & 5 & 6 & 7 & 7 & 8 \\
\hline $\mathbf{T}$ & 8 & 7 & 6 & 5 & 5 & 5 & 5 & 4 & 3 & 4 & 5 & 6 & 7 & 8 \\
\hline $\mathbf{I}$ & 9 & 8 & 7 & 6 & 6 & 5 & 6 & 5 & 4 & 4 & 5 & 5 & 6 & 7 \\
\hline $\mathbf{O}$ & 10 & 9 & 8 & 7 & 7 & 6 & 6 & 6 & 5 & 4 & 5 & 6 & 6 & 7 \\
\hline $\mathbf{N}$ & 11 & 10 & 9 & 8 & 8 & 7 & 6 & 7 & 6 & 5 & 5 & 6 & 7 & 7 \\
\hline $\mathbf{A}$ & 12 & 11 & 10 & 9 & 9 & 8 & 7 & 6 & 7 & 6 & 6 & 6 & 6 & 7 \\
\hline $\mathbf{L}$ & 13 & 12 & 11 & 10 & 10 & 9 & 8 & 7 & 7 & 7 & 7 & 7 & 7 & 6 \\
\hline
\end{tabular}

Fig. 1. Dynamic programming matrices for determining the Levenshtein distance between (a) "compute" and "combinatorial" and (b) "computational" and "combinatorial."

\subsection{Keyword and author analysis}

Keywords provide an important indication of the subjects covered in scientific studies. An analysis of these keywords can therefore provide an overview of the most important topics in a research field. These keywords could be examined with the help of bibliometrix. However, in its web interface biblioshiny, the exact strings $x$ and $y$ are compared to each other. If one character of a string is different from the other string, then these words are considered to be different keywords. For this reason, a separate keyword analysis algorithm was developed in MATLAB for this review. The algorithm considers similar strings as one keyword. The similarity of the strings is determined by the Levenshtein (1966) distance. The Levenshtein distance between $x$ and $y$ is the total cost of transforming $x$ into $y$ using the operations of inserting, deleting, and substituting a character. Thereby, the string distance problem is equivalent to the shortest path problem defined in a graph which is constructed as follows (Spiliopoulos and Sofianopoulou, 2007).

Given strings $x$ and $y$ of lengths $m$ and $n$, respectively, the nodes are the points $(i, j)$ in the grid $i=$ $0, \ldots, m$ and $j=0, \ldots, n$, whereby the former string is put vertically and the latter string horizontally. There are three types of directed links from the nodes $i$ and $j$ (Spiliopoulos and Sofianopoulou, 2007):

- vertical links $(i, j) \rightarrow(i+1, j), i=0, \ldots, m-1, j=0, \ldots, n$, with cost 1 , to represent the deletion of $x_{i+1}$

- horizontal links $(i, j) \rightarrow(i, j+1), i=0, \ldots, m, j=0, \ldots, n-1$, with cost 1 , to represent the insertion of $y_{j+1}$ after $x_{i}$ (if $i=0$, at the start of $x$ );

- diagonal links $(i, j) \rightarrow(i+1, j+1), i=0, \ldots, m-1, j=0, \ldots, n-1$, to represent the substitution of $x_{i+1}$ by $y_{j+1}$. There is no cost involved if $x_{i+1}=y_{j+1}$, otherwise the cost is 1 .

The distance between strings $x$ and $y$ is then given by the length of the shortest path between points $(0,0)$ and $(m, n)$ (Spiliopoulos and Sofianopoulou, 2007). Figure 1 shows two examples of determining Levenshtein distances in the so-called dynamic programming matrices. The top rows 
of the matrices have 0 values, since the insertions at the start of the vertical string are not penalized. After filling in the matrices according to the above-mentioned links, the minimum value in the last row shows the distance. In the first example in Fig. 1a, there are three substitutions (P-U and E with $\mathrm{B}-\mathrm{I}$ and $\mathrm{A}$ ) and six insertions ( $\mathrm{N}$ and $\mathrm{O}-\mathrm{R}-\mathrm{I}-\mathrm{A}-\mathrm{L})$, whereas in the second example there are only six substitutions (P-U-T with B-I-N and I-O-N with O-R-I, cf. Fig. 1b).

In the developed algorithm, the Levenshtein distance is used to match equivalent strings under one keyword. Thus, the number of keyword occurrences can be determined more accurately. Strings of five or more characters are grouped for a Levenshtein distance up to one and strings of nine or more characters are grouped for a Levenshtein distance up to two. The latter case should ensure that, for example, the plural of a word and the simultaneous use of a hyphen is recognized as the same keyword (e.g. metaheuristic and meta-heuristics). Besides the number of keyword occurrences, the algorithm also determines the mean publication year and the mean citations of all articles with the respective keyword. In addition, the algorithm examines the keywords with regard to their simultaneous occurrence in the same articles (cf. Section 3.4). This latter function is also used to identify the collaboration of authors (cf. Fig. A1). The MATLAB script is applicable to any other bibliometric analysis and can be provided upon request.

\section{Results}

In the following, the main characteristics of the research field on $\mathrm{CO}$ are presented (cf. Section 3.1). Afterwards, an overview of contributions and collaborations of different countries and organizations is given in Section 3.2. Subsequently, the most relevant sources and studies are highlighted (cf. Section 3.3), before the most relevant topics on $\mathrm{CO}$ are discussed (cf. Section 3.4).

\subsection{Development of the research field}

The research field on CO includes 8393 articles, which have been published in 1415 different sources at the time of this analysis. A total of 14,423 authors were involved in the articles and the average number of citations per document is 23.55 . This high citation rate is due to some highly cited publications (cf. Section 3.3); 55\% of the articles are cited less than 10 times. The number of publications per year on CO has increased quite steadily over the years from 13 in 1990 to 533 in 2019. This could be related to the general increase in publications in the field of operations research. However, when comparing the share of articles on $\mathrm{CO}$ with the total number of articles on optimization in general (search query optimization in general in Table 1), a slight increase can be observed: in 1990, 15,868 articles on optimization in general and $76(0.5 \%)$ on $\mathrm{CO}$ had already appeared, and in 2019, the share is $0.8 \%$ with 8456 in the total number of $1,100,191$ publications.

\subsection{Publication distribution and collaboration of countries, organizations, and authors}

In total, authors from 85 countries have contributed to articles on $\mathrm{CO}$. The fact that $\mathrm{CO}$ is only extensively researched in a limited number of countries is shown by the share of the top 20 relevant 
countries in Table 3, which, with a number of 7157 articles, are involved in $85 \%$ of the publications on CO. In the top 20 are Australia, 11 countries from Europe, 5 from Asia, and 3 from America. By far the most articles were authored by researchers from the United States $(23 \%)$, followed by China $(14 \%)$, France (8\%), Germany (7\%), and Japan (7\%). The development of the number of articles in these top five relevant countries in Fig. 2a is of interest: while authors in the United States published the most articles each year from 1990 to 2013, China was responsible for the fewest publications in the 1990s. However, the number of annual articles by Chinese authors has been increasing almost exponentially since then, and since 2014 most of the annual articles on CO are written by Chinese authors. Furthermore, as the arrow icons in Table 3 show, the annual percentage increase in the number of articles since 2015 among the top 20 countries is the highest in China (cf. Section 2.3). This could be related to the rapid growth of the Chinese economy and the associated increase in energy consumption (Zhang et al., 2017). As Section 3.4.3 shows, the production sector and the energy sector are the most important application areas of $\mathrm{CO}$ research.

However, these numbers of published articles do not provide any indication of the importance of $\mathrm{CO}$ research in the overall research of a country. For this reason, the total publications of a country are also shown in Table 3 in relation to the mean annual (between 2012 and 2018) gross domestic expenditure on R\&D of the respective country (UNESCO, 2020). In the top five most productive countries, with the exception of France, $\mathrm{CO}$ seems to be of comparatively low importance. In contrast, CO research seems to be of great priority in Portugal, Iran, Spain, Belgium, and Canada. In addition, the United States has by far the highest number of citations $(67,298)$ and the highest $h$-index (104), $g$-index (212), and $m$-index (3.47). However, in terms of average article citations, the United States is only in sixth position (35.1), behind Australia (41.5), Belgium (40.9), Canada (40.8), England (36.8), and Switzerland (35.2). Due to the high number of citations, the $g$-index in these countries is also comparatively high. In relation to the number of publications, the $m$-index is high in some countries, such as Iran, which published its first articles on CO in 2001.

Most collaborative publications have been produced by authors from United States and China (146), United States and Canada (73), United States and Germany (69), United States and France (60) as well as England and China (55). Using the corresponding author for assigning the articles to a country (cf. Table 3), the countries that frequently participate in international cooperation can be identified. Switzerland (48\%) has the largest share of collaborative publications, ahead of Belgium (45\%) and Austria (40\%). In contrast, authors from Iran ( $88 \%$ single country publications) and Taiwan $(85 \%)$ show the lowest share of collaborative publications. In general, the share of international or intranational collaboration is rather low, which is also reflected by the number of single-authored publications $(1.087 ; 12 \%)$.

A total of 3539 different organizations from the 85 countries were participating in the publications on CO. The top 20 of the most relevant organizations are listed in Table 4 . These organizations have been involved in 1696 publications (20\%) so far. Most of the articles have originated from authors of the top five organizations French National Centre for Scientific Research (253, France), University of California System (162, United States), Chinese Academy of Sciences (118, China), National Institute for Research in Digital Science and Technology (115, France), and Massachusetts Institute of Technology (101, United States). However, it should be noted that some of these organizations are associations of several institutions, such as the Chinese Academy of Sciences or the University of California System. The annual publication volume of these five organizations in Fig. $2 b$ shows a slightly rising trend in addition to annual fluctuations. The trend in the annual 


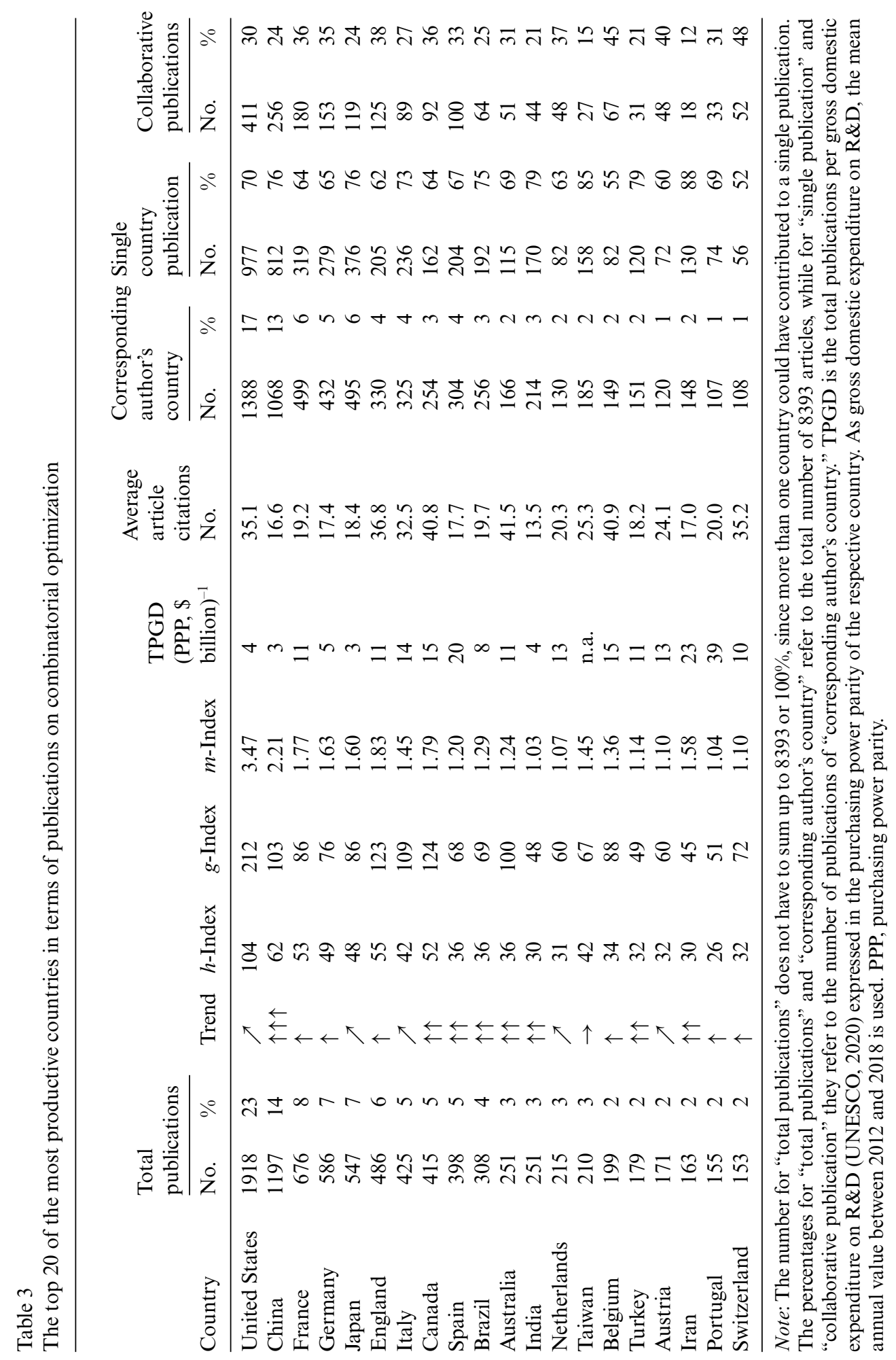


(a)

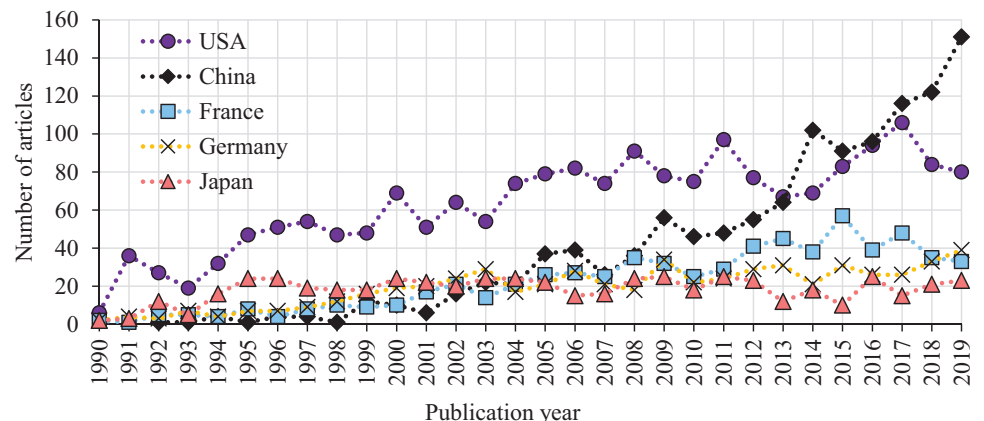

(b)

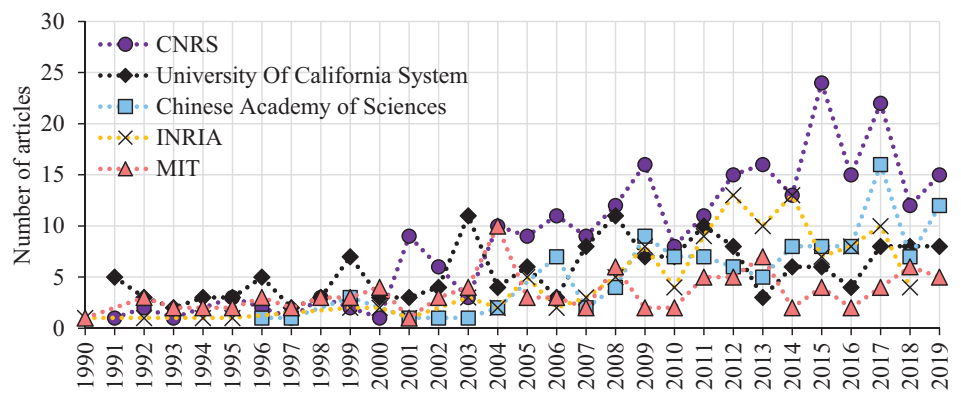

Publication year

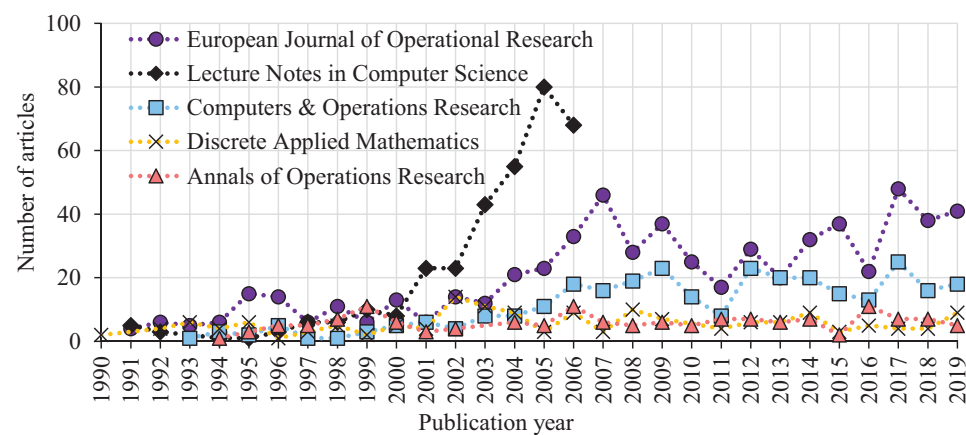

Publication year

(d)

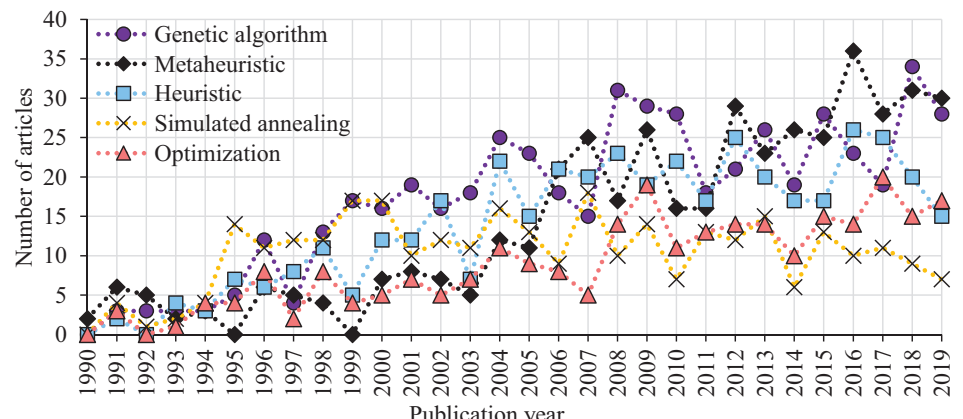

Fig. 2. Annual development of publications of the top five most productive countries (a), organizations (b), sources (c), and keywords (d). For reasons of clarity, zero values are not displayed. Web of Science stopped covering articles from the source Lecture Notes in Computer Science in 2007.

(C) 2021 The Authors. International Transactions in Operational Research published by John Wiley \& Sons Ltd on behalf of International Federation of Operational Research Societies 
Table 4

The top 20 of the most productive organizations in terms of publications on combinatorial optimization

\begin{tabular}{|c|c|c|c|c|c|c|c|}
\hline \multirow[b]{2}{*}{ Organization } & \multirow[b]{2}{*}{ Country } & \multicolumn{2}{|c|}{$\begin{array}{l}\text { Total } \\
\text { publications }\end{array}$} & \multirow[b]{2}{*}{ Trend } & \multirow[b]{2}{*}{$h$-Index } & \multirow[b]{2}{*}{$g$-Index } & \multirow[b]{2}{*}{$m$-Index } \\
\hline & & No. & $\%$ & & & & \\
\hline $\begin{array}{l}\text { French National Centre for } \\
\text { Scientific Research (CNRS) }\end{array}$ & France & 253 & 3 & $\uparrow$ & 31 & 52 & 1.07 \\
\hline University of California System & United States & 162 & 2 & $\uparrow$ & 37 & 62 & 1.28 \\
\hline Chinese Academy of Sciences & China & 118 & 1 & $\uparrow \uparrow \uparrow$ & 20 & 41 & 0.83 \\
\hline $\begin{array}{l}\text { National Institute for Research } \\
\text { in Digital Science and } \\
\text { Technology (INRIA) }\end{array}$ & France & 115 & 1 & $\uparrow$ & 25 & 39 & 0.83 \\
\hline $\begin{array}{l}\text { Massachusetts Institute of } \\
\text { Technology (MIT) }\end{array}$ & United States & 101 & 1 & $\nearrow$ & 30 & 70 & 1.00 \\
\hline $\begin{array}{l}\text { State University System of } \\
\text { Florida }\end{array}$ & United States & 101 & 1 & $\uparrow$ & 25 & 41 & 1.04 \\
\hline University of Montreal & Canada & 89 & 1 & $\uparrow$ & 27 & 67 & 0.93 \\
\hline Universite Libre de Bruxelles & Belgium & 88 & 1 & $\uparrow$ & 22 & 75 & 0.88 \\
\hline University System of Georgia & United States & 84 & 1 & $\uparrow \uparrow \uparrow$ & 25 & 53 & 0.89 \\
\hline University of Bologna & Italy & 80 & 1 & $\uparrow$ & 22 & 46 & 0.88 \\
\hline University of Tokyo & Japan & 78 & 1 & $\uparrow \uparrow \uparrow$ & 21 & 41 & 0.84 \\
\hline Carnegie Mellon University & United States & 65 & 1 & $\uparrow$ & 23 & 48 & 0.79 \\
\hline Tsinghua University & China & 64 & 1 & $\uparrow$ & 19 & 40 & 0.73 \\
\hline University of Texas System & United States & 64 & 1 & $\uparrow$ & 17 & 45 & 0.63 \\
\hline $\begin{array}{l}\text { Huazhong University of Science } \\
\text { and Technology }\end{array}$ & China & 63 & 1 & $\uparrow \uparrow \uparrow$ & 25 & 41 & 1.25 \\
\hline $\begin{array}{l}\text { Indian Institute of Technology } \\
\text { System (IIT System) }\end{array}$ & India & 63 & 1 & $\uparrow \uparrow$ & 15 & 29 & 0.54 \\
\hline $\begin{array}{l}\text { Nanyang Technological } \\
\text { University }\end{array}$ & Singapore & 63 & 1 & $\uparrow$ & 27 & 41 & 1.08 \\
\hline Russian Academy of Sciences & Russia & 63 & 1 & $\uparrow \uparrow$ & 9 & 16 & 0.31 \\
\hline $\begin{array}{l}\text { Polytechnic University of } \\
\text { Catalonia }\end{array}$ & Spain & 62 & 1 & $\uparrow \uparrow$ & 19 & 47 & 0.79 \\
\hline Universidade de Lisboa & Portugal & 62 & 1 & $\uparrow \uparrow$ & 17 & 39 & 0.68 \\
\hline
\end{tabular}

Note: The percentage values refer to the total of 8393 publications.

percentage increase in publications (cf. Table 4) shows a particularly strong increase for Chinese Academy of Sciences, University System of Georgia, University of Tokyo, and Huazhong University of Science and Technology. The publications on CO from the University Of California System have the highest $h$-index (37), followed by the French National Centre for Scientific Research (31) and the Massachusetts Institute of Technology (30). However, the order changes when the number of citations is taken into account for the most cited articles: for the $g$-index, the Universite Libre de Bruxelles (75) is at the top of the list, ahead of the Massachusetts Institute of Technology (70) and the University of Montreal (67). The publications of the University of California System and Huazhong University of Science and Technology are particularly relevant with regard to the first publication year, with $m$-indexes of 1.28 and 1.25 , respectively. The majority of collaborations took place between organizations of the same country (cf. Fig. 3): most collaborations were conducted 


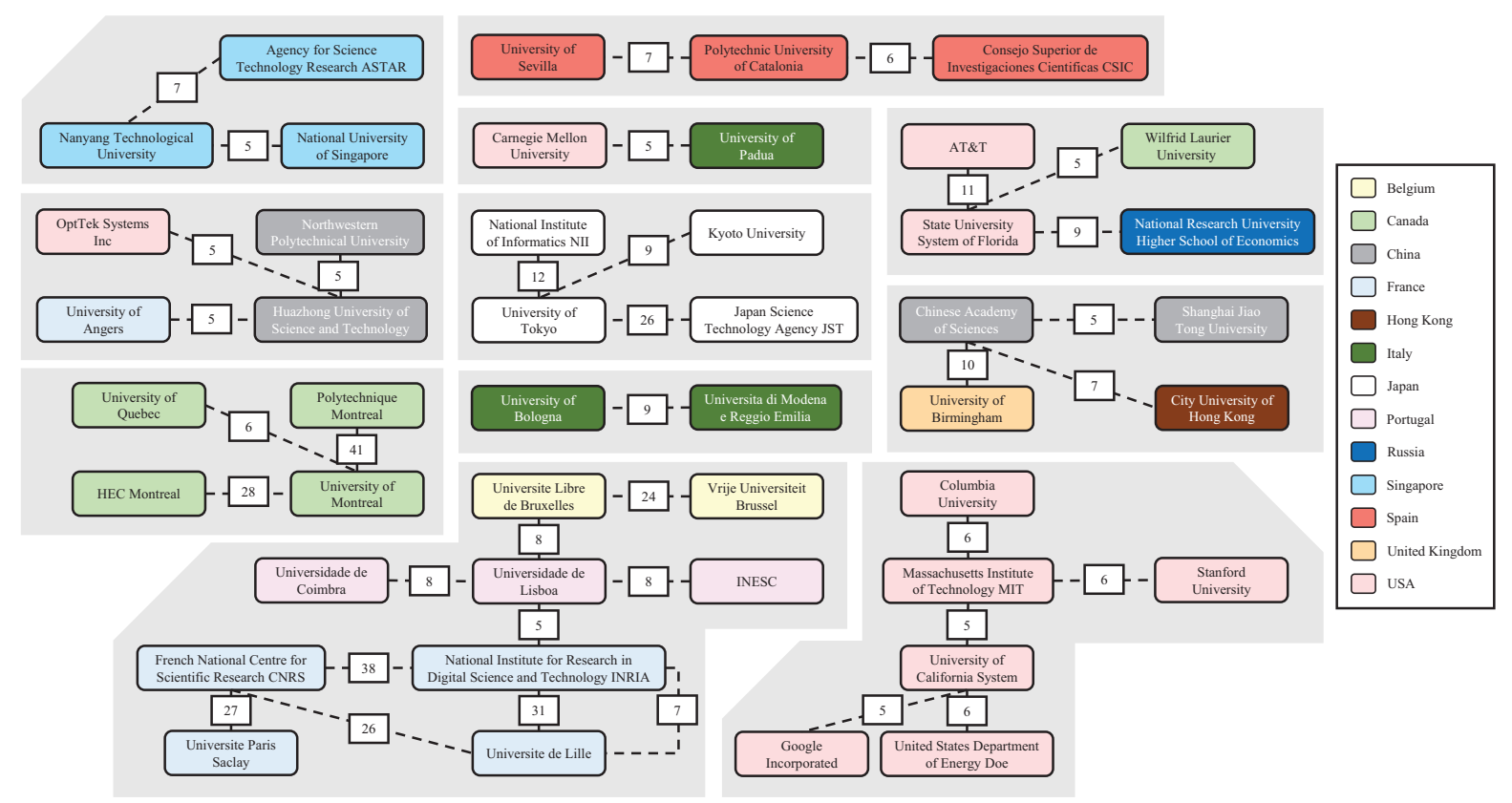

Fig. 3. Collaboration network of the top 20 most productive organizations together with their top three most productive collaborations. Collaborations with less than five collaborative publications are not shown.

by the University of Montreal and Polytechnique Montreal (41), the French National Centre for Scientific Research and the National Institute for Research in Digital Science and Technology (38) as well as the National Institute for Research in Digital Science and Technology and the University of Lille (31). The publication distribution and collaboration of the most relevant authors can be found in the Appendix.

\subsection{Most relevant sources and articles}

In addition to the authors of the articles, it is also important to analyze the sources in which the articles are published predominantly. The studies on CO have been published in 1415 different sources. A large proportion of the articles on CO (35\%) is published in the top 20 most productive sources (cf. Table 5) European Journal of Operational Research (EJOR), Lecture Notes in Computer Science (LNCS), Computers \& Operations Research, Discrete Applied Mathematics, and Annals of Operations Research. Most articles on CO were published in EJOR, with 7\% of all publications. Therefore, it is not surprisingly that this source has the highest $h$-index (58) and $g$-index (99), followed by Computers \& Operations Research regarding the $h$-index (46) and by LNCS regarding the $g$-index (87). The source Expert Systems with Applications has a particularly high $m$-index (2.07) due to a high $h$-index (31) in relation to the starting year of the first publication on CO (2005). In the most relevant source, EJOR, the share of articles on $\mathrm{CO}$ in all publications has increased 
Table 5

The top 20 of the most productive scientific sources in terms of publications on combinatorial optimization

\begin{tabular}{|c|c|c|c|c|c|c|c|}
\hline \multirow[b]{2}{*}{ Source } & \multicolumn{2}{|c|}{$\begin{array}{l}\text { Total } \\
\text { publications } \\
\text { (TP) }\end{array}$} & \multirow[b]{2}{*}{ Trend } & \multirow{2}{*}{$\begin{array}{l}\text { Average article } \\
\text { citations }\end{array}$} & \multirow[b]{2}{*}{$h$-Index } & \multirow[b]{2}{*}{$g$-Index } & \multirow[b]{2}{*}{$m$-Index } \\
\hline & No. & $\%$ & & & & & \\
\hline $\begin{array}{l}\text { European Journal of } \\
\text { Operational Research }\end{array}$ & 615 & 7 & $\uparrow$ & 26 & 58 & 99 & 2.00 \\
\hline $\begin{array}{l}\text { Lecture Notes in Computer } \\
\quad \text { Science }\end{array}$ & 335 & 4 & - & 29 & 28 & 87 & 0.97 \\
\hline $\begin{array}{l}\text { Computers \& Operations } \\
\quad \text { Research }\end{array}$ & 306 & 4 & $\nearrow$ & 8 & 46 & 44 & 1.70 \\
\hline $\begin{array}{l}\text { Discrete Applied } \\
\text { Mathematics }\end{array}$ & 158 & 2 & $\nearrow$ & 25 & 23 & 58 & 0.77 \\
\hline $\begin{array}{l}\text { Annals of Operations } \\
\quad \text { Research }\end{array}$ & 149 & 2 & $\nearrow$ & 8 & 31 & 31 & 1.19 \\
\hline $\begin{array}{l}\text { Journal of Combinatorial } \\
\text { Optimization }\end{array}$ & 138 & 2 & $\uparrow \uparrow$ & 24 & 17 & 53 & 0.74 \\
\hline Mathematical Programming & 125 & 1 & $\rightarrow$ & 18 & 30 & 43 & 1.03 \\
\hline Applied Soft Computing & 120 & 1 & $\uparrow \uparrow \uparrow$ & 24 & 25 & 46 & 1.56 \\
\hline $\begin{array}{l}\text { Expert Systems with } \\
\text { Applications }\end{array}$ & 120 & 1 & $\nearrow$ & 24 & 31 & 51 & 2.07 \\
\hline $\begin{array}{l}\text { Computers \& Industrial } \\
\text { Engineering }\end{array}$ & 110 & 1 & $\uparrow \uparrow$ & 24 & 25 & 48 & 0.93 \\
\hline Journal of Heuristics & 108 & 1 & $\nearrow$ & 22 & 30 & 47 & 1.36 \\
\hline $\begin{array}{l}\text { Theoretical Computer } \\
\text { Science }\end{array}$ & 87 & 1 & $\uparrow$ & 17 & 19 & 33 & 0.73 \\
\hline $\begin{array}{l}\text { International Journal of } \\
\text { Production Research }\end{array}$ & 82 & 1 & $\uparrow \uparrow$ & 14 & 23 & 30 & 0.82 \\
\hline Operations Research Letters & 79 & 1 & $\nearrow$ & 21 & 18 & 39 & 0.62 \\
\hline $\begin{array}{l}\text { Journal of the Operational } \\
\text { Research Society }\end{array}$ & 76 & 1 & $\nearrow$ & 28 & 21 & 46 & 0.72 \\
\hline $\begin{array}{l}\text { Journal of Global } \\
\text { Optimization }\end{array}$ & 70 & 1 & $\nearrow$ & 7 & 18 & 19 & 0.69 \\
\hline Discrete Optimization & 66 & 1 & $\nearrow$ & 31 & 13 & 44 & 0.93 \\
\hline Information Sciences & 65 & 1 & $\uparrow$ & 13 & 22 & 27 & 0.85 \\
\hline Algorithmica & 61 & 1 & $\uparrow$ & 21 & 13 & 33 & 0.45 \\
\hline $\begin{array}{l}\text { Computational Optimization } \\
\text { and Applications }\end{array}$ & 60 & 1 & $\nearrow$ & 11 & 19 & 23 & 0.83 \\
\hline
\end{tabular}

Note: The percentage values refer to the total of 8393 publications. The trend in number of publications is not shown for the Lecture Notes in Computer Science, since this source is not indexed in Web of Science since 2007.

steadily, from $2 \%$ in 1990 to $6 \%$ in 2019. In addition to the findings from Section 3.1, this again demonstrates the increasing importance of $\mathrm{CO}$ in the research field of operations research.

However, when examining the development of the annual publications of the top five most relevant sources in Fig. 2c, it is striking that the annual publications of LNCS increased exponentially between 2001 and 2005. If this trend had continued, LNCS would have been in first rank among the most productive sources on CO. However, from 2007 onward, no publications by LNCS are listed 
in Web of Science anymore. A reason for this could be that LNCS publishes mostly conference proceedings. The trend in the annual percentage increase in publications shows a strong upward trend for only a few sources, with Applied Soft Computing at the top (cf. Table 5).

The articles in a research field that are most cited can be assessed as most influential to that field. Table A2 lists the 20 globally most cited articles in the CO research area. Many of these articles are about newly developed metaheuristics like ant colony optimization (Dorigo et al., 1996; Dorigo and Gambardella, 1997), harmony search (Geem et al., 2001), or variable neighborhood search (Mladenović and Hansen, 1997). The study by Dorigo et al. (1996) on ant colony optimization is cited most frequently (5646). Furthermore, there are some articles in the top 20 that deal with the development of new algorithms (evolutionary algorithms, Yao et al., 1999; Han and Kim, 2002; approximation algorithms, Goemans and Williamson, 1995) or the enhancement of existing metaheuristics (MAX-MIN ant system, Stützle and Hoos, 2000). It is notable that the newly developed metaheuristics are mostly tested and benchmarked using the TSP (Dorigo et al., 1996; Dorigo and Gambardella, 1997; Mladenović and Hansen, 1997; Stützle and Hoos, 2000; Geem et al., 2001). The studies described in this paragraph also have by far the most local citations, that is, within the 8393 articles examined here. This means that these fundamental new methods are either applied or extended in many other articles. Ant colony optimization is the most common method with four studies in the top 20 of the most cited articles (Dorigo et al., 1996; Dorigo and Gambardella, 1997; Stützle and Hoos, 2000; Dorigo and Blum, 2005).

In addition to the development of these theoretical approaches, $\mathrm{CO}$ methods are applied in case studies in the top 20 articles, such as vision/image processing (Boykov and Kolmogorov, 2004; Boykov and Funka-Lea, 2006; Jaqaman et al., 2008), quantum computers (Knill et al., 2001), or atomic decomposition (Donoho and Huo, 2001). In contrast to the studies on developments of metaheuristics and algorithms described above, the local citations of these articles on specific applications are very low. Furthermore, only 2 of the top 20 most cited articles were published in the top 5 most relevant sources: one each in EJOR and Computers \& Operations Research (cf. Table A2).

However, the most cited articles described above do not provide a complete picture of research trends in CO, as many are relatively old with the most recent article dating from 2008. Therefore, Table 6 shows the top 10 articles with the highest annual citation rates that have appeared since 2010. With 108 citations, Deng et al. (2019) is cited the most annually. Similar to the sixth most cited study by Nouiri et al. (2018), a new particle swarm optimization method is developed in Deng et al. (2019). An advanced method, in this case a search algorithm, is also introduced in Wen and Yin (2013). Some other studies are more application-oriented on phosphorus systems for white light emitting diodes (Xia et al., 2016), biological transport networks (Tero et al., 2010), or fatty acids production (Xu et al., 2013).

Furthermore, three survey studies are included in Table 6: first, on hyperheuristics (Burke et al., 2013), that is, heuristics that choose an appropriate solution heuristic depending on the problem. The other two publications are strongly linked regarding their content. Sörensen (2015) discusses the fact that many metaheuristics have been developed in recent years and that these are largely based on metaphors about natural or man-made processes, for example, ant or bee colony optimization. The author argues that besides some innovative studies of high quality, many papers have been published that are justified only by the fact that the developed metaheuristics are based on novel metaphors. Blum et al. (2011) also motivate their study on hybrid metaheuristics by the 
Table 6

Articles among the scientific contributions on combinatorial optimization, which have the highest annual citation rate since 2010

\begin{tabular}{|c|c|c|c|c|}
\hline \multirow[b]{2}{*}{ Article title } & \multicolumn{2}{|c|}{ Global citations } & \multirow{2}{*}{$\begin{array}{l}\text { Publication } \\
\text { year }\end{array}$} & \multirow[b]{2}{*}{ Source } \\
\hline & No. & Per year & & \\
\hline $\begin{array}{l}\text { A novel intelligent diagnosis } \\
\text { method using optimal LS-SVM } \\
\text { with improved PSO algorithm } \\
\text { (Deng et al., 2019) }\end{array}$ & 108 & 108 & 2019 & Soft Computing \\
\hline $\begin{array}{l}\text { Recent developments in the new } \\
\text { inorganic solid-state LED } \\
\text { phosphors (Xia et al., 2016) }\end{array}$ & 264 & 66 & 2016 & Dalton Transactions \\
\hline $\begin{array}{l}\text { Quantum annealing with } \\
\text { manufactured spins (Johnson } \\
\text { et al., 2011) }\end{array}$ & 533 & 59 & 2011 & Nature \\
\hline $\begin{array}{l}\text { Hyperheuristics: a survey of the } \\
\text { state of the art (Burke et al., } \\
\text { 2013) }\end{array}$ & 354 & 51 & 2013 & $\begin{array}{l}\text { Journal of the Operational } \\
\text { Research Society }\end{array}$ \\
\hline $\begin{array}{l}\text { Metaheuristics - the metaphor } \\
\text { exposed (Sörensen, 2015) }\end{array}$ & 223 & 45 & 2015 & $\begin{array}{l}\text { International Transactions in } \\
\text { Operational Research }\end{array}$ \\
\hline $\begin{array}{l}\text { An effective and distributed } \\
\text { particle swarm optimization } \\
\text { algorithm for flexible job-shop } \\
\text { scheduling problem (Nouiri } \\
\text { et al., 2018) }\end{array}$ & 82 & 41 & 2018 & $\begin{array}{l}\text { Journal of Intelligent } \\
\text { Manufacturing }\end{array}$ \\
\hline $\begin{array}{l}\text { Rules for biologically inspired } \\
\text { adaptive network design (Tero } \\
\text { et al., 2010) }\end{array}$ & 375 & 38 & 2010 & Science \\
\hline $\begin{array}{l}\text { Modular optimization of } \\
\text { multigene pathways for fatty } \\
\text { acids production in } E \text {. coli }(\mathrm{Xu} \\
\text { et al., 2013) }\end{array}$ & 262 & 37 & 2013 & Nature Communications \\
\hline $\begin{array}{l}\text { Hybrid metaheuristics in } \\
\text { combinatorial optimization: a } \\
\text { survey (Blum et al., 2011) }\end{array}$ & 323 & 36 & 2011 & Applied Soft Computing \\
\hline $\begin{array}{l}\text { A feasible method for } \\
\text { optimization with orthogonality } \\
\text { constraints (Wen and Yin, 2013) }\end{array}$ & 225 & 32 & 2013 & Mathematical Programming \\
\hline
\end{tabular}

fact that research on metaheuristics for $\mathrm{CO}$ problems was mostly algorithm-oriented in the past. Nevertheless, the authors see a trend that the focus of research on CO metaheuristics is shifting from this algorithm orientation to a problem orientation. As a result, metaheuristics are now often hybridized with other optimization techniques in order to find the best approaches to solving problems.

As already described, the article by Dorigo et al. (1996) has the most global citations (5646) among the articles examined here and is also very often locally cited (235) by these 8393 studies. However, five studies are even more frequently cited locally by the 8393 articles (cf. Table 7). The 
Table 7

Five most frequently cited references in the articles on combinatorial optimization

\begin{tabular}{|c|c|c|c|}
\hline Article title & $\begin{array}{l}\text { Local } \\
\text { citations }\end{array}$ & $\begin{array}{l}\text { Publication } \\
\text { year }\end{array}$ & Source \\
\hline $\begin{array}{l}\text { Computers and intractability: a guide to the theory of } \\
\text { NP-completeness (Garey and Johnson, 2009) }\end{array}$ & 911 & 1979 & $\begin{array}{l}\text { A Series of Books in the } \\
\text { Mathematical Sciences }\end{array}$ \\
\hline $\begin{array}{l}\text { Optimization by simulated annealing (Kirkpatrick } \\
\text { et al., 1983) }\end{array}$ & 702 & 1983 & Science \\
\hline $\begin{array}{l}\text { Genetic algorithms in search, optimization, and } \\
\text { machine learning (Goldberg, 2012) }\end{array}$ & 527 & 1989 & - \\
\hline Tabu search—part I (Glover, 1989) & 276 & 1989 & $\begin{array}{l}\text { ORSA Journal on } \\
\text { Computing }\end{array}$ \\
\hline $\begin{array}{l}\text { "Neural" computation of decisions in optimization } \\
\text { problems (Hopfield and Tank, 1985) }\end{array}$ & 266 & 1985 & Biological Cybernetics \\
\hline
\end{tabular}

focus of the most local cited study is on the identification and handling of NP-complete (combinatorial optimization) problems, that is, problems that can be solved in polynomial time on a nondeterministic turing machine (Garey and Johnson, 2009). The other three publications in Table 7 deal with the introduction of new metaheuristics (simulated annealing, Kirkpatrick et al., 1983, and tabu search, Glover, 1989) or a review of a metaheuristic (genetic algorithm, Goldberg, 2012). These three metaheuristics are also the most frequently employed in the 8393 studies on CO (cf. Section 3.4).

\subsection{Most relevant subjects}

In this section, first the algorithm based on the Levenshtein distance is evaluated (cf. Section 3.4.1). Second, the most relevant keywords and thus topics in the research area of CO are shown in Section 3.4.2. Section 3.4.3 then attempts to determine the most relevant application areas of CO.

\subsubsection{Evaluation of keyword algorithm}

The developed algorithm led to a much better recognition of related keywords than was the case with the web interface biblioshiny of the R-tool bibliometrix. For example, different spellings with or without hyphen or in singular or plural are now combined. The keyword combinatorial optimization, which occurs most frequently in the articles with 3.051 times, serves as an example. The different spellings that have been grouped for this keyword are the following, whereby the change in spelling compared to the first keyword is shown in bold: combinatorial optimization, combinatorial optimization $\boldsymbol{S}$, combinatorial optimiSation, combinatorial optimiSationS, and combinatoriC optimization. Thus 7\% more appearances of the keyword combinatorial optimization could be identified (cf. Fig. 4). For the seven most relevant keywords shown in Fig. 4, the greatest improvement was achieved for the keyword genetic algorithm: here the recognition rate increased by $99 \%$. However, there are also examples that seem to be always stated in the same way: for simulated annealing, the developed algorithm yielded no improvement. 


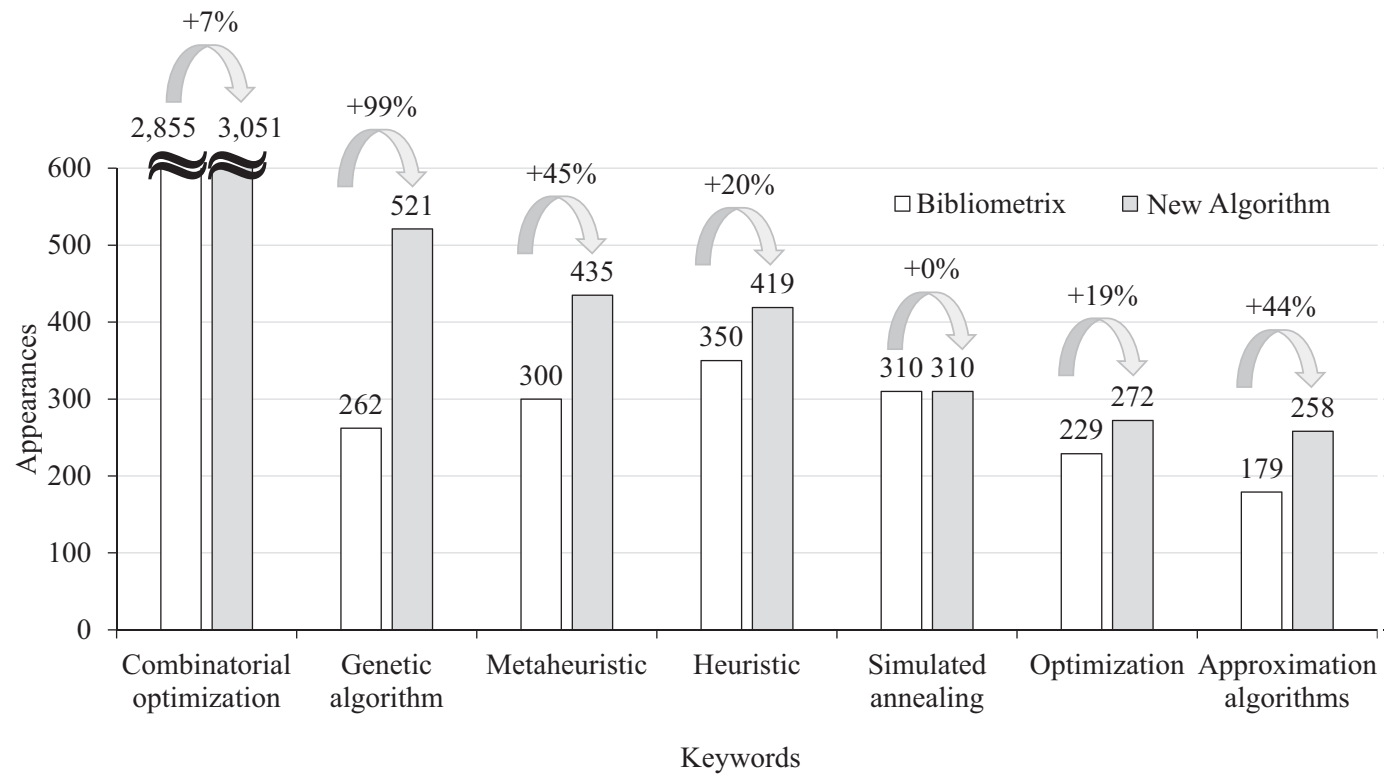

Fig. 4. Comparison of the appearance of the most relevant keywords determined on the one hand with the R-tool bibliometrix and on the other hand with the new algorithm developed for this study.

\subsubsection{Combinatorial optimization problems and solution methods}

In this section, the most relevant keywords on $\mathrm{CO}$ that appear in at least $1 \%$ of publications are discussed. As already shown in Section 3.4.1, the keyword combinatorial optimization occurs most frequently (in 3051 publications). This is not surprising since the keyword corresponds to the overall topic of this bibliometric analysis and thus the search query in Web of Science. Therefore, the keyword combinatorial optimization is excluded in the following analysis. Thus, the top five relevant keywords are genetic algorithm (521 occurrences), metaheuristic (435), heuristic (419), simulated annealing (310), and optimization (272). The annual occurrence of these keywords fluctuates, but in general there is an increasing trend (except for simulated annealing, cf. Fig. 2d). The fact that simulated annealing is less frequently covered in actual $\mathrm{CO}$ publications is further demonstrated by the low mean publication year (2005.7, cf. Fig. 5). In Fig. 5, the 25 keywords that appear in at least $1 \%$ of publications are divided into different categories and their mean publication year is shown. In addition, the correlation matrix in Fig. 6, which shows how often these keywords occur together in articles, is also relevant for the following analysis.

The most frequently addressed specific optimization problems are the TSP (225 appearances), integer programming (225), and the scheduling problem (219). While no clear trend can be identified for integer programming, the TSP is mainly investigated in connection with the metaheuristics ant colony optimization (20), genetic algorithms (18) as well as local search (16), and the scheduling problem with tabu search (13) and simulated annealing (10) (cf. Fig. 6). The TSP is examined so frequently since it is representative of $\mathrm{CO}$ problems. If an efficient (polynomial-time) algorithm could be found for the TSP, then efficient algorithms could also be found for all other NP-complete problems (Hoffman et al., 2013). Integer programming problems (e.g., assignment problem) are 
J.M. Weinand et al. / Intl. Trans. in Op. Res. 0 (2021) 1-39

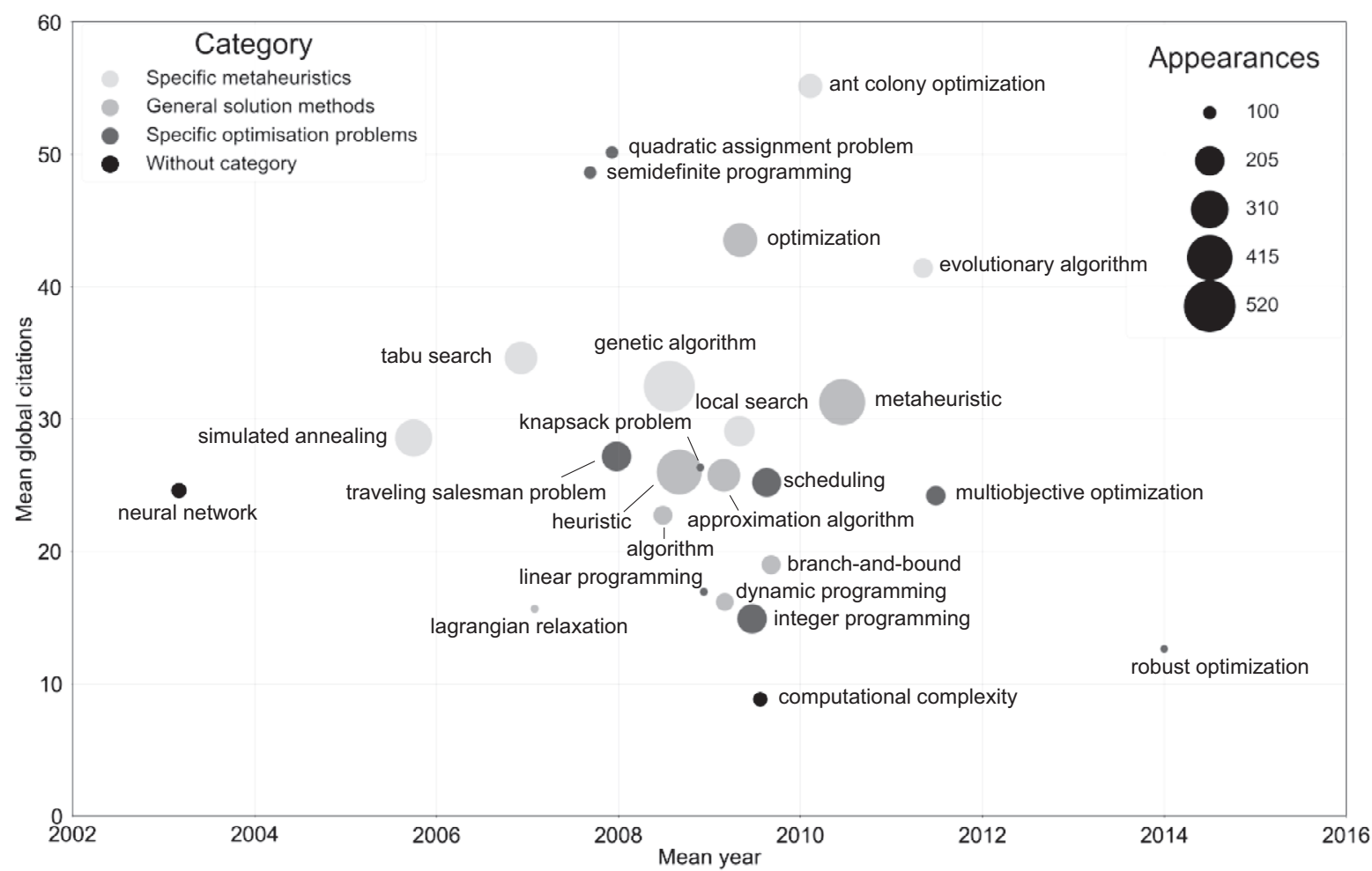

Fig. 5. The top 25 most relevant keywords on $\mathrm{CO}$ with their number of appearances, mean global citations, and mean publication year in the 8393 articles.

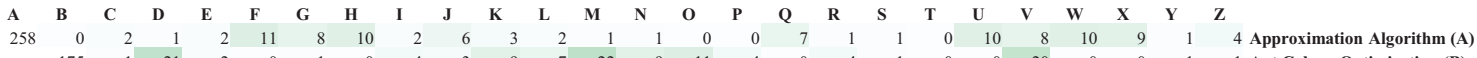

$$
\begin{aligned}
& \begin{array}{rrrrrrrrrrrrrrrrrrrrrrrrrr}
175 & 1 & 21 & 2 & 0 & 1 & 0 & 4 & 3 & 9 & 7 & 22 & 9 & 11 & 4 & 0 & 4 & 1 & 0 & 0 & 20 & 0 & 0 & 1 & 1 \text { Ant Colony Optimization (B) } \\
& 141 & 12 & 3 & 0 & 1 & 9 & 6 & 10 & 13 & 5 & 12 & 3 & 2 & 3 & 1 & 0 & 0 & 0 & 0 & 2 & 0 & 3 & 3 & 1
\end{array} \\
& \begin{array}{llllllllllllllllllllllll}
141 & 12 & 3 & 0 & 1 & 9 & 6 & 10 & 13 & 5 & 12 & 3 & 2 & 3 & 1 & 0 & 0 & 0 & 0 & 2 & 0 & 3 & 3 & 1 \text { Evolutionary Algorithm (C) }
\end{array} \\
& \begin{array}{rrrrrrrrrrrrrrrrrrrrrrr}
521 & 9 & 0 & 1 & 14 & 33 & 24 & 18 & 35 & 32 & 35 & 54 & 13 & 3 & 9 & 1 & 1 & 2 & 18 & 0 & 0 & 3 & 4 \text { Genetic Algorithm (D) }
\end{array}
\end{aligned}
$$

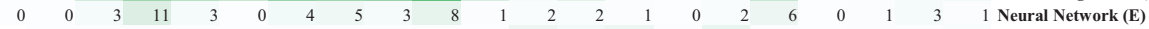

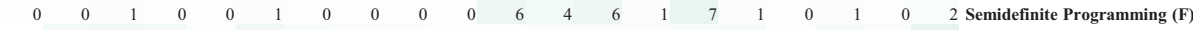

$$
\begin{aligned}
& \begin{array}{rrrrrrrrrrrrrrrrrrr}
4 & 5 & 4 & 0 & 5 & 2 & 1 & 1 & 0 & 0 & 1 & 1 & 1 & 2 & 3 & 0 & 3 & 1 & 8 \text { Algorithm (G) }
\end{array}
\end{aligned}
$$

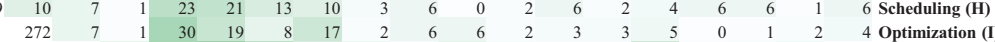

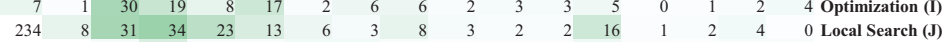

$$
\begin{aligned}
& \begin{array}{llllllllllllllll}
140 & 3 & 12 & 2 & 2 & 4 & 4 & 2 & 0 & 1 & 1 & 5 & 1 & 0 & 2 & 2 \text { Multi-Objective Optimization (K) }
\end{array}
\end{aligned}
$$

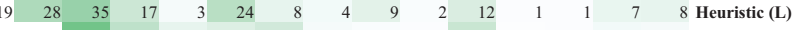

$$
\begin{aligned}
& \begin{array}{llllllllllllll}
435 & 48 & 22 & 8 & 11 & 15 & 3 & 2 & 1 & 18 & 0 & 1 & 4 & 3 \text { Metaheuristic (M) }
\end{array} \\
& \begin{array}{lllllllllllll}
257 & 34 & 3 & 2 & 13 & 1 & 2 & 0 & 3 & 1 & 0 & 1 & 3 \text { Tabu Search (N) }
\end{array}
\end{aligned}
$$

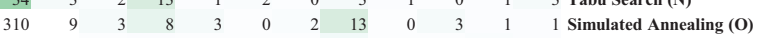

$$
\begin{aligned}
& \begin{array}{rrrrrrrrrrr}
84 & 0 & 1 & 0 & 0 & 0 & 4 & 0 & 0 & 2 & 1 \text { Particle Swarm Optimization (P) }
\end{array} \\
& \begin{array}{llllllllll}
225 & 1 & 5 & 8 & 9 & 7 & 3 & 5 & 7 & 6 \text { Integer Programming (Q) }
\end{array} \\
& \begin{array}{rrrrrrrr}
0 & 4 & 0 & 12 & 1 & 3 & 0 & 0 \text { Quadratic Assignment Problem (R) } \\
84 & 5 & 3 & 1 & 1 & 0 & 1 & 3
\end{array} \\
& 3 \text { Lagrangian Relaxation (S) } \\
& 842511007 \text { Branch-and-Bound (T) } \\
& \begin{array}{lllll}
225 & 1 & 7 & 3 & 4 \\
& 83 & 7 & 4 & 6 \text { Traveling Salesman Problem (V) }
\end{array} \\
& \begin{array}{llll}
83 & 7 & 4 & 6 \text { Robust Optimization (W) }
\end{array}
\end{aligned}
$$

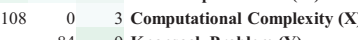

$$
\begin{aligned}
& 84 \quad 9 \text { Knapsack Problem (Y) } \\
& 128 \text { Dynamic Programming (Z) }
\end{aligned}
$$

Fig. 6. Correlation matrix of the most relevant keywords in the research field of combinatorial optimization. The numbers indicate how often the keywords appear together in publications. The darker the fields in the matrix are colored green, the more often these keywords appear together.

(C) 2021 The Authors. International Transactions in Operational Research published by John Wiley \& Sons Ltd on behalf of International Federation of Operational Research Societies 
also often closely related to CO (Conforti et al., 2014). However, not every CO problem can be formulated as an integer programming problem, if its feasible region is infinite (Ibaraki, 1976). The scheduling problem is often used for decision support, for example, in the case of project scheduling in project management (Hartmann and Briskorn, 2010), personnel scheduling (van den Bergh et al., 2013), or maintenance scheduling (Froger et al., 2016).

The keywords with the highest mean publication year represent the most recent topics in CO. The two most recent of the specific optimization problems are robust optimization (mean publication year: 2014.0) and multiobjective optimization (2011.4). This is also demonstrated by the trends in the annual percentage increase in publications on these topics since 2015. The difficulties, that several objectives have to be optimized simultaneously and that not all parameters are known in advance, are often encountered when applying optimization techniques to real-world problems (Schmidt et al., 2019). The method of robust optimization includes several approaches to protect a decision maker against parameter ambiguity and stochastic uncertainty. Thereby, the manager must determine what it means for him to have a robust solution. Based on worst-case analysis, a solution is evaluated using the realization of the most unfavorable uncertainty (Gabrel et al., 2014). Multiobjective optimization involves optimizing multiple objectives at the same time by selecting a (Pareto)efficient solution that cannot be improved in one objective without worsening it in another objective. In recent years, the concepts of both areas have been combined into multiobjective robust optimization (Schmidt et al., 2019).

The most prominent general solution techniques for solving these $\mathrm{CO}$ problems are metaheuristics (435 appearances), heuristics (419), optimizations (272), and approximation algorithms (258) (cf. Fig. 5). Real-world CO problems are usually large and exact solution procedures are mostly inadequate. Hence heuristics are mainly used in practice to solve complex CO problems (Hertz and Widmer, 2003). In the past, typically specialized heuristics were developed. However, this approach changed over the years: more general (metaheuristics) and less specialized solution approaches emerged. The motivation here is that applying a metaheuristic to a specific problem or problem class requires less effort than developing a specialized heuristic from scratch (Gendreau and Potvin, 2005). For heuristics and metaheuristics, for certain inputs good solutions (i.e., close to the optimal solution of a problem) are determined, but it is often uncertain why the heuristics work well. In this context, approximation algorithms are helpful, which bring mathematical rigor to the study of heuristics. Thus, it can be proven how well a heuristic performs on all instances and an idea of the types of instances on which a heuristic does not perform well can be given (Williamson and Shmoys, 2011).

Furthermore, many different specific metaheuristics are included in the 8393 studies (cf. Fig. 5). Various taxonomies can be found in the literature to distinguish metaheuristics (see Zäpfel et al., 2010). To give one example: Hertz and Widmer (2003) distinguish metaheuristics by two principles, namely local search and population search. The authors define the local search methods as an intensive exploration of the solution space by moving from the current solution to another promising solution in the neighborhood at each iteration. In comparison, the population search consists of maintaining a variety of good solutions and combining them to produce better solutions. The three metaheuristics most frequently found in the 8393 studies on CO are among the classic examples of population search and local search: genetic algorithm (521 occurrences; population search) as well as simulated annealing (310; local search), and tabu search (257; local search). These three metaheuristics are also often considered jointly in studies having at least 34 shared occurrences (c.f.

(C) 2021 The Authors.

International Transactions in Operational Research published by John Wiley \& Sons Ltd on behalf of International Federation of Operational Research Societies 
Fig. 6). The ant colony optimization, which is so frequently covered in the top 20 most cited articles, is also among the most relevant specific metaheuristics with 175 appearances. The articles on ant colony optimization are most cited on average (55, cf. Fig. 5) followed by articles on particle swarm optimization (52) and articles on quadratic assignment problems (50). For more information on the chronological development of the research field of metaheuristics please refer to Sörensen et al. (2018). Information on the most important topics of countries, organizations and sources can be found in Table A3.

\subsubsection{Application areas for combinatorial optimization}

In addition to the analysis of keywords, which can contain a multitude of words, an analysis with single words has also been conducted with the MATLAB algorithm. In this case, the keywords are divided into individual words, that is, combinatorial optimization, for example, into combinatorial and optimization. This is done in order to identify important application areas for CO methods. Table A4 lists the single keywords that appear in at least $1 \%$ of publications on CO. In this table, the words that are identified as specific real-world application areas of $\mathrm{CO}$ (and not specific problems or methods as in Fig. 5) are written in bold and the most relevant keywords and sources for the articles of these application areas are shown. The articles of a potential application area were checked by a manual inspection. For example, scheduling, traveling, or vehicle could represent application areas, but these keywords refer almost exclusively to the CO problems scheduling problem, TSP or the vehicle routing problem, respectively.

A total of 12 application areas were identified (cf. keywords written in bold in Table A4). The following four areas are covered most frequently (in 2\% of all 8393 articles each): production, data, power, and management. The research field of production, which is about production planning (e.g., Shishvan and Sattarvand, 2015) or assembly (e.g., Becker and Scholl, 2009), for example, is also strongly linked to the application field manufacturing (e.g., Amen, 2006). Companies nowadays operate in global production networks (Lanza et al., 2019), which is the consequence of intense offshoring, outsourcing, global procurement, and expansion into new international markets. Therefore, the global production network of a typical multinational manufacturing company today includes plants spread across the globe, each facing increasing pressure to coordinate its operations with one another and with the rest of the supply chain (Ferdows et al., 2016). Research in the field of $\mathrm{CO}$ on the application area of production also has a comparatively high mean publication year (2011.1), which demonstrates the increasing need for novel problem solutions in this area.

The research field of data is linked to information and these two application areas mainly focus on data mining (e.g., Brandner et al., 2013) or information theory (e.g., Braun et al., 2017), respectively. New approaches are needed in these areas, as the flood of data in recent decades have exceeded the ability to process, analyze, store, and understand the data sets. A good example is web pages whose number has increased from 1 million to 1 trillion between 1998 and 2008 alone (Fan and Bifet, 2013). The associated increasing use of data mining technologies also has a direct influence on the application field of information: for example, the increasingly emerging approaches of privacypreserving data mining aim to protect sensitive information of individuals (Xu et al., 2014).

Big data is also related to the energy sector, which is increasingly using smart meters (sensor and measurement devices in smart grids) to collect data on real-time electricity consumption in order to better forecast and shift electrical loads (Wen et al., 2018). Energy sector related issues, which 
are often NP-hard (Goderbauer et al. 2019), seem to be the most frequently represented subjects in publications on $\mathrm{CO}$, with the keywords power and energy. The topic of power is mainly about the above-mentioned smart grid (e.g., Meskina et al., 2018) applications or optimal power flow (e.g., Abido, 2002) calculations. Relevant topics in the field of energy include energy efficiency (e.g., Alharbi et al., 2019), and energy consumption (e.g., Weinand et al., 2019). In the course of the energy system transition to reduce anthropogenic greenhouse gas emissions, these issues are becoming increasingly important. This is also reflected by the mean publication year of the application area energy (2011.7), which is the most actual among the 12 identified application fields (cf. Table A4). Due to the developments in industrial production already discussed above, the greenhouse gas emissions increase further, therefore energy research is also increasingly connected with the application field of production. Due to improved technologies and companies, which are increasingly trying to make their production planning energy efficient, the emissions do not increase linear. Some reasons for this from a company's perspective are policy/legislation, scarcity of resources, rising energy prices and an increasing environmental awareness (Biel and Glock, 2016).

The last two major fields of application which are covered in more than $100 \mathrm{CO}$ articles are management with many supply chain management studies (e.g., Mohammadi Bidhandi et al., 2009) and decision with mainly studies about decision support systems (e.g., Haastrup et al., 1998). Supply chain management studies are obviously strongly tied to production and decision support is actually needed in each of the application areas.

The analysis demonstrates the importance of CO methods, which are applied in many different fields and are used to solve many of the current global problems. In addition, it is notable that in many of these application areas, genetic algorithms are mainly used to solve the underlying problems. This metaheuristic already turned out to be the most relevant in the area of CO (cf. Section 3.4.2). Furthermore, this single-word analysis also confirms the presumptions that robust optimization is currently the most prominent topic on CO, since the two strongly related terms robust and uncertainty show the highest mean publication years 2013.8 and 2013.3, respectively (cf. Table A4). The consideration of uncertainties also becomes increasingly relevant for the realworld application areas discussed above like production planning (e.g., inhomogeneity of products, Mundi et al., 2019) or energy system analysis (e.g., stochastic nature of renewables and unknown future global energy and economy outlook, Mavromatidis et al., 2018).

\section{Discussion}

In this section, the results are reflected in terms of the challenges and prospects of the research field, separated for (meta)heuristics (cf. Section 4.1) and exact algorithms (cf. Section 4.2). Furthermore, the limitations of the study are discussed in Section 4.3.

\subsection{Challenges and prospects of (meta)heuristics}

One overarching conclusion from the data presented in this paper is that a large majority of papers in the field of CO are still of the "problem-algorithm-results" type. In these papers, an algorithm for a specific $\mathrm{CO}$ problem is developed and tested, and in most cases demonstrated to perform well by

(C) 2021 The Authors.

International Transactions in Operational Research published by John Wiley \& Sons Ltd on behalf of International Federation of Operational Research Societies 
comparing it to other algorithms for the same problem. Several authors (Barr et al., 1995; Hooker, 1995; Kendall et al., 2016) have warned that this type of research, especially the competitive testing aspect, yields very little scientific knowledge beyond the anecdotal. It wastes enormous amounts of research time on "development" activities (polishing code, compiler tuning, etc.) necessary to achieve top-notch performance. Papers in which attempts are made to draw some generalizable conclusions on heuristics and metaheuristics exist (e.g., Watson et al., 2003; Santini et al., 2018), but still represent a marginal phenomenon.

The practice of deciding which papers to publish based on competitive testing (which has been called the "horse race") has also resulted in a considerable publication bias. Mainly positive results (algorithm $X$ works well for problem $Y$ ) appear in the literature and negative results, which demonstrate that some type of heuristic does not work for some problem (category), are few and far between (although some exist, e.g., Sörensen and Schittekat, 2013). Combined with the fact that there are very few generally accepted protocols for testing and reporting on algorithmic results, most academic journals do not even require simple statistical tests to demonstrate that a "better performance" is significant in the statistical sense. This makes one wonder how well many of the results published in the literature would stand the scrutiny of independent replication and testing (see, e.g., Sörensen et al., 2019, where an independent replication was not able to confirm the authors' original performance claims).

Another observation is that there seems to be a widening divide between the communities on metaphor-based metaheuristics (also called "nature-inspired" metaheuristics, even though the inspiration for this category of metaheuristics now comes from sources that have little to do with nature), and the more traditional metaheuristics that are not based on some metaphor. In the field of metaphor-based metaheuristics, the decision on whether an algorithmic idea is valuable or not seems to hinge on the novelty of the metaphor that inspired it, with ever more outlandish metaphors being proposed (interior decoration, Gandomi, 2014; the FIFA world cup, Razmjooy et al., 2016; "intelligent" water drops, Hosseini, 2009; and-in a demonstration of spectacular opportunismthe spread of covid-19, Martínez-Álvarez et al., 2020). ${ }^{2}$ Without implying that the field of traditional metaheuristics does not have its issues, one can only conclude that the scientific standards in the subfield of metaphor-based metaheuristics are particularly low. As an illustration, it is remarkable that one of the top-cited papers in this field is the paper introducing the harmony search algorithm (Geem et al., 2001) (cf. Section 3.3). This metaheuristic is supposedly based on musicians playing music together (a solution in harmony search lingo is called a "melody," for example), even though this algorithm has been unequivocally demonstrated (Weyland, 2010, 2015) to be a special case of evolution strategies, a metaheuristic that predates it by 30 years. The community project "Metaheuristics in the Large" (MitL) has recently formulated a framework that enables combinatorial assembly and comparison of metaheuristics, and thereby also addresses issues of reproducibility and scalability (Swan et al. 2020).

Another trend, that is perhaps difficult to glean from the bibliometric results in this paper is that there is an increasing focus on "rich" problems (i.e., problems with complex formulations that involve many specific constraints and objectives), often based on real-life applications. Without doubt, heuristic, and metaheuristic ideas have penetrated into the mindsets of practitioners that

\footnotetext{
${ }^{2}$ The interested reader is referred to the "EC Bestiary," a satirical compilation of all metaphor-inspired metaheuristics published in the literature (Campelo and Aranha, 2019).
}

(C) 2021 The Authors. International Transactions in Operational Research published by John Wiley \& Sons Ltd on behalf of International Federation of Operational Research Societies 
develop software for real-life optimization, and increasingly, (meta)heuristic research is finding its way to practical application. As an illustration, (software) companies like PTV and ORTEC increasingly participate in conferences and write out challenges for researchers to solve their real-life problems (Kheiri et al., 2019).

Finally, researchers in the field of (meta)heuristics are increasingly reaching out to related fields, incorporating ideas and techniques to develop better optimization algorithms. The combination of heuristics with exact methods (often called "matheuristics") has developed into a field of its own. Combinations with constraint programming and machine learning are also increasingly being found. For a concise review of such combinations, please refer to Talbi (2016).

\subsection{Challenges and prospects of exact algorithms}

The main keywords concerning publications on exact $\mathrm{CO}$ algorithms, according to the data reported in this work, are branch-and-bound and integer programming. Also from the data, the number of publications related to exact algorithms is considerably less than those related to approximation algorithms. One reason for this is that many hard combinatorial problems of practical interest are NP-hard and only approximation methods are able to provide good solutions. However, exact algorithms for NP-hard problems that are able to solve a number of real network instances with millions of nodes to proven optimality, have recently been described (e.g., San Segundo et al., 2016; Walteros and Buchanan. 2020).

Another explanation for the relatively small number of publications concerning exact $\mathrm{CO}$ algorithms might lie in the already mentioned "problem-algorithm-results" structure of the papers. Typically, this line of work focuses on the study of the specific structure of problem instances and develops specialized new algorithms, which are then compared extensively with the current state-ofthe-art approaches. Only algorithms that show a significant improvement over state-of-the-art get to be published in the top $\mathrm{CO}$ journals. In addition, it has been argued that exact algorithms should also be certifying, that is, provide an easily verifiable proof that the solution is correct (Gocht et al., 2020).

Notwithstanding, this "problem-algorithm-results" stream of research has shown some exciting improvements for some fundamental NP-hard/NP-complete problems, such as the maximum independent set problem and the Boolean satisfiability (SAT) problem. Specifically, for the latter and during the past 20 years, the progress on the algorithmic methods has been reported to have at least the same impact as the advances in hardware (Fichte et al., 2020). In addition, research on specific NP-complete problems has also led to the study of effective transformations between problems. Among the many examples of recent successful transformations, SAT modules of state-of-the-art constraint programming solvers can be pointed out (e.g., Zhou et al., 2015) as well as the SAT-based bounding functions used by state-of-the-art maximum clique solvers ( $\mathrm{Li}$ et al., 2018). Complementary to the development of new exact algorithmic techniques are the numerous $\mathrm{CO}$ challenges that are organized periodically, such as XCSP3, PACE, DIMACS, and SAT competitions, where algorithms are compared against benchmarks of practical interest and the state-of-the-art is settled.

From the data available, it is also worth mentioning the study of methods that aim at speeding up the convergence of exact $\mathrm{CO}$ algorithms by reducing the problem instance exploiting structural properties. These techniques can be applied just once, in a preprocessing phase known as 
kernelization. Alternatively, they can be applied at every node of the branching tree, denoted the branch-and-reduce paradigm. Both techniques have recently contributed to solve to proven optimality some hard combinatorial large-scale problem instances (Akiba and Iwata, 2016; Hespe et al., 2020). Future research in exact CO algorithms capable of solving large-scale real-life problems will definitely continue over time. Exciting developments are to be expected from new algorithmic branch-and-bound and branch-and-reduce techniques, but one may also look forward to new algorithmic frameworks, of which the recent branch-cut-and-prize framework for vehicle routing and other related problems are good examples (Pessoa et al., 2020).

Since these challenges and prospects refer mostly to the results of Section 3, other emerging issues are likely to be neglected. One example would be machine learning based approaches, which show promising results in different applications by making decisions that were otherwise made by handcrafted expert knowledge-based heuristics in a more principled and optimized way (Bengio et al., 2020). For example, in the original AlphaGo paper (Silver et al., 2016), a machine learning algorithm is first trained based on expert knowledge and refined in a further step using a reward signal from games of self-play (reinforcement learning). In general, machine learning is used in both exact and heuristic frameworks (Bengio et al., 2020).

\subsection{Limitations of this study}

As with all review studies, the evaluation of the topic in this bibliometric analysis depends on the type of search query. Most probably, a large number of studies cover CO problems, but do not use combinatorial optimization, neither as a keyword, nor in the title, abstract, or article body. The search among the Keywords Plus increases the chance that a representative sample of articles on $\mathrm{CO}$ has been investigated because these keywords are generated from titles and phrases that appear in the references of an article. This means, that on the basis of a specialized algorithm, a search across disciplines is performed for all the articles that have cited references in common (Clarivate, 2021). However, if these publications are also not assigned to CO via Keywords Plus in Web of Science, they are not included in the present analysis. Thus, a 100\% comprehensive picture of CO cannot be given. For example, the search query "optimi*" results in about 1 million articles, some of which might involve CO problems. On the other hand, the objective is to analyze studies that explicitly deal with $\mathrm{CO}$ as a methodology and the analyzed corpus of literature is assumed to yield a representative sample of the $\mathrm{CO}$ research field. In addition, the search query was limited to peerreviewed original research articles, as is common in bibliometric analyses. As a consequence, some important contributions in the research field, such as the Handbook of Combinatorial Optimization (Pardalos et al., 2013) or the Handbook of Heuristics (Martí et al., 2018), are not covered.

Furthermore, some methods use parameters that are set in a more or less arbitrary way, and different parameters may yield different results. Examples are the number of years in the trend analysis, or the maximum distance set for the Levenshtein distance. It is not possible to recognize all relevant keywords during the grouping process using distances such as the Levenshtein distance, because this always involves some interpretation. For example, Fig. 5 shows the keyword traveling salesman problem, which is used 225 times. The higher occurrence (cf. Table A4) of the words traveling (384) and salesman (349), however, suggests that the TSP is covered in more than 225 articles. However, not all articles can be grouped by an algorithm if significantly different keywords

(C) 2021 The Authors.

International Transactions in Operational Research published by John Wiley \& Sons Ltd on behalf of International Federation of Operational Research Societies 
are used. For example, unlike simulated annealing, which is always known under that name, large neighborhood search is also known as destroy-and-repair and ruin-and-recreate, but the automatic analysis does not (and cannot) group these concepts. Therefore, the keyword analysis in Section 3.4 is only to be understood as an indication of trends.

\section{Summary and conclusions}

More and more real-world problems are becoming highly complex and have to be solved with combinatorial optimization techniques, which have always been of great interest to the scientific community. Consequently, the number of publications on combinatorial optimization has increased exponentially between 1990 and 2019, amounting to 8393 at the time of this analysis. This requires a study of the corpus of literature to show the status quo and trends in research on combinatorial optimization. The present study therefore uses a bibliometric analysis, supported by the literature database Web of Science, the R-tool bibliometrix as well as a novel algorithm developed for keyword analyses.

Among the 85 contributing countries, the United States is the most important contributor with 1918 articles and the highest $h$-index (104), followed by China (1197 articles), with the highest annual number of publications since 2014, and France (676 articles). In general, the share of collaborative publications on combinatorial optimization studies is rather low, with the most collaborations between United States and China (146). The most productive organizations are the French National Centre for Scientific Research (235 articles), the University of California System with 162 articles as well as the highest $h$-index (37) and the Chinese Academy of Sciences (118 articles). Due to the low proportion of cross-country collaborations, organizations from the same country tend to collaborate, with the University of Montreal and Polytechnique Montreal recording the highest number of collaborations among institutes (42). Core sources on combinatorial optimization are EJOR, LNCS, and Computers \& Operations Research, which published around $15 \%$ of the 8393 articles.

The analysis of the most relevant publications and author keywords shows that the majority of studies focuses on the development, extension, and application of metaheuristics. While in most cases genetic algorithms predominate (6\% of the 8393 publications), metaheuristics are mostly tested or applied to the TSP. Among the most globally cited publications are several articles on ant colony optimization. It appears that in the past the development of metaheuristics required only a new type of metaphor to justify its development. In this context, there seems to be a widening divide between the communities on metaphor-based metaheuristics (also called "nature-inspired" metaheuristics) and the more traditional metaheuristics that are not based on some metaphor. However, this trend of algorithm orientation in metaheuristics seems to have partly changed to a more problem-oriented approach in recent years. In this context, the analysis of the keywords showed that combinatorial optimization problems are particularly relevant in real-world application areas in the energy sector, production sector, and data management. This is due to the need to solve complex problems related to global production networks, the reduction of greenhouse gas emissions in the course of energy system transition, and the increasing amount of big data and its processing. The most current topics in the research area of combinatorial optimization are uncertainties and the associated increasingly relevant methodology of robust optimization, which is also becoming 
more and more important in the aforementioned application areas. A discussion of the challenges and prospects of the field further reveals that most articles are still of the "problem-algorithmresults" type, which requires large amounts of research time on "development" activities necessary to achieve top-notch performance.

The present bibliometric analysis demonstrates global research trends in combinatorial optimization. This study can therefore support the scientific community as well as policy makers in identifying relevant issues regarding the expanding and transforming combinatorial optimization research area and its real-world applications.

\section{Acknowledgments}

This work has been partially funded by the Spanish Ministry of Science, Innovation, and Universities through the project COGDRIVE (DPI2017-86915-C3-3-R). In this context, we would also like to thank the Karlsruhe Institute of Technology.

Open access funding enabled and organized by Projekt DEAL.

\section{References}

Abido, M.A., 2002. Optimal power flow using particle swarm optimization. International Journal of Electrical Power \& Energy Systems 24, 7, 563-571.

Akiba, T., Iwata, Y., 2016. Branch-and-reduce exponential/FPT algorithms in practice: a case study of vertex cover. Theoretical Computer Science 609, 211-225.

Alharbi, F., Tian, Y.-C., Tang, M., Zhang, W.-Z., Peng, C., Fei, M., 2019. An ant colony system for energy-efficient dynamic virtual machine placement in data centers. Expert Systems with Applications 120, 228-238.

Amen, M., 2006. Cost-oriented assembly line balancing: model formulations, solution difficulty, upper and lower bounds. European Journal of Operational Research 168, 3, 747-770.

Aria, M., Cuccurullo, C., 2017. bibliometrix: an R-tool for comprehensive science mapping analysis. Journal of Informetrics 11, 4, 959-975.

Barr, R.S., Golden, B.L., Kelly, J.P., Resende, M.G.C., Stewart, W.R., 1995. Designing and reporting on computational experiments with heuristic methods. Journal of Heuristics 1, 1, 9-32.

Becker, C., Scholl, A., 2009. Balancing assembly lines with variable parallel workplaces: problem definition and effective solution procedure. European Journal of Operational Research 199, 2, 359-374.

Bengio, Y., Lodi, A., Prouvost, A., 2020. Machine learning for combinatorial optimization: a methodological tour d'horizon. European Journal of Operational Research 290, 405-421.

Biel, K., Glock, C.H., 2016. Systematic literature review of decision support models for energy-efficient production planning. Computers \& Industrial Engineering 101, 243-259.

Bjorndal, M.H., Caprara, A., Cowling, P.I., Della Croce, F., Lourenço, H., Malucelli, F., Orman, A.J., Pisinger, D., Rego, C., Salazar, J.J., 1995. Some thoughts on combinatorial optimisation. European Journal of Operational Research 83, 2, 253-270.

Blum, C., 2005. Ant colony optimization: introduction and recent trends. Physics of Life Reviews 2, 4, 353-373.

Blum, C., Puchinger, J., Raidl, G.R., Roli, A., 2011. Hybrid metaheuristics in combinatorial optimization: a survey. Applied Soft Computing 11, 6, 4135-4151.

Blum, C., Roli, A., 2003. Metaheuristics in combinatorial optimization. ACM Computing Surveys 35, 3, $268-308$.

Boykov, Y., Funka-Lea, G., 2006. Graph cuts and efficient N-D image segmentation. International Journal of Computer Vision 70, 2, 109-131.

Boykov, Y., Kolmogorov, V., 2004. An experimental comparison of min-cut/max-flow algorithms for energy minimization in vision. IEEE Transactions on Pattern Analysis and Machine Intelligence 26, 9, 1124-1137.

(C) 2021 The Authors. International Transactions in Operational Research published by John Wiley \& Sons Ltd on behalf of International Federation of Operational Research Societies 
Brandner, H., Lessmann, S., Voß, S., 2013. A memetic approach to construct transductive discrete support vector machines. European Journal of Operational Research 230, 3, 581-595.

Braun, G., Jain, R., Lee, T., Pokutta, S., 2017. Information-theoretic approximations of the nonnegative rank. Computational Complexity 26, 1, 147-197.

Burke, E.K., Gendreau, M., Hyde, M., Kendall, G., Ochoa, G., Özcan, E., Qu, R., 2013. Hyper-heuristics: a survey of the state of the art. Journal of the Operational Research Society 64, 12, 1695-1724.

Cacchiani, V., Malaguti, E., Toth, P., 2018. Applied combinatorial optimization. European Journal of Operational Research. Available at https://www.journals.elsevier.com/european-journal-of-operational-research/call-for-papers/ applied-combinatorial-optimization (accessed 28 March 2020).

Campelo, F., Aranha, C., 2019. EC-BESTIARY: a bestiary of evolutionary, swarm and other metaphor-based algorithms. Available at https://fcampelo.github.io/EC-Bestiary/ (accessed 19 July 2020).

de Castro, L.N, von Zuben, F.J., 2002. Learning and optimization using the clonal selection principle. IEEE Transactions on Evolutionary Computation 6, 3, 239-251.

Clarivate (2021) KeyWords Plus generation, creation, and changes. Available at https://support.clarivate.com/ ScientificandAcademicResearch/s/article/KeyWords-Plus-generation-creation-and-changes?language=en_US (accessed on 3 February 2021).

Conforti, M., Cornuéjols, G., Zambelli, G. (eds), 2014. Integer Programming, Springer International Publishing, Cham.

Cook, W., 2019. Computing in combinatorial optimization. In Steffen, B., Woeginger, G. (eds) Computing and Software Science: State of the Art and Perspectives, Springer International Publishing, Cham, pp. 27-47.

Deng, W., Yao, R., Zhao, H., Yang, X., Li, G., 2019. A novel intelligent diagnosis method using optimal LS-SVM with improved PSO algorithm. Soft Computing 23, 7, 2445-2462.

Donoho, D.L., Elad, M., 2003. Optimally sparse representation in general (nonorthogonal) dictionaries via 1 minimization. Proceedings of the National Academy of Sciences 100, 5, 2197-2202.

Donoho, D.L., Huo, X., 2001. Uncertainty principles and ideal atomic decomposition. IEEE Transactions on Information Theory 47, 7, 2845-2862.

Dorigo, M., Blum, C., 2005. Ant colony optimization theory: a survey. Theoretical Computer Science 344, 2-3, 243-278.

Dorigo, M., Gambardella, L.M., 1997. Ant colonies for the travelling salesman problem. Biosystems 43, 2, 73-81.

Dorigo, M., Maniezzo, V., Colorni, A., 1996. Ant system: optimization by a colony of cooperating agents. IEEE Transactions on Systems, Man and Cybernetics, Part B (Cybernetics) 26, 1,29-41.

Egghe, L., 2006. Theory and practise of the g-index. Scientometrics 69, 1, 131-152.

Eskandarpour, M., Dejax, P., Miemczyk, J., Péton, O., 2015. Sustainable supply chain network design: an optimizationoriented review. Omega 54, 11-32.

Fan, W., Bifet, A., 2013. Mining big data. ACM SIGKDD Explorations Newsletter 14, 2, 1-5.

Feo, T.A., Resende, M.G.C., 1995. Greedy randomized adaptive search procedures. Journal of Global Optimization 6, 2, $109-133$.

Ferdows, K., Vereecke, A., de Meyer, A., 2016. Delayering the global production network into congruent subnetworks. Journal of Operations Management 41, 1, 63-74.

Fichte, J.K., Hecher, M., Szeider, S., 2020. A time leap challenge for SAT-solving. In Simonis, H. (ed.) Principles and Practice of Constraint Programming: 26th International Conference, CP 2020, Louvain-la-Neuve, Belgium, September 7-11, pp. 267-285.

Froger, A., Gendreau, M., Mendoza, J.E., Pinson, É., Rousseau, L.-M., 2016. Maintenance scheduling in the electricity industry: a literature review. European Journal of Operational Research 251, 3, 695-706.

Gabrel, V., Murat, C., Thiele, A., 2014. Recent advances in robust optimization: an overview. European Journal of Operational Research 235, 3, 471-483.

Gandomi, A.H., 2014. Interior search algorithm (ISA): a novel approach for global optimization. ISA transactions 53, 4, $1168-1183$.

Garey, M.R., Johnson, D.S., 2009. Computers and Intractability: A Guide to the Tof NP-Completeness (27th edn). Freeman, New York.

Geem, Z.W., Kim, J.H., Loganathan, G.V., 2001. A new heuristic optimization algorithm: harmony search. Simulation $76,2,60-68$. 
Gendreau, M., Potvin, J.-Y., 2005. Metaheuristics in combinatorial optimization. Annals of Operations Research 140, 1, 189-213.

Gerkey, B.P., Matarić, M.J., 2016. A formal analysis and taxonomy of task allocation in multi-robot systems. The International Journal of Robotics Research 23, 9, 939-954.

Glover, F., 1989. Tabu search-part I. ORSA Journal on Computing 1, 3, 190-206.

Gocht, S., McBride, R., McCreesh, C., Nordström, J., Prosser, P. and Trimble, J., 2020. Certifying solvers for clique and maximum common (connected) subgraph problems. In Simonis, H. (ed.) Principles and Practice of Constraint Programming: 26th International Conference, CP 2020, Louvain-la-Neuve, Belgium, September 7-11, pp. 338-357.

Goderbauer, S., Comis, M., Williamowski, F.J.L., 2019. The synthesis problem of decentralizes energy systems is strongly NP-hard. Computers \& Chemical Engineering 124, 343-349.

Goemans, M.X., Williamson, D.P., 1995. Improved approximation algorithms for maximum cut and satisfiability problems using semidefinite programming. Journal of the ACM (JACM) 42, 6, 1115-1145.

Goldberg, D.E., 2012. Genetic Algorithms in Search, Optimization, and Machine Learning (30th edn). Addison-Wesley, Boston, MA.

Haastrup, P., Maniezzo, V., Mattarelli, M., Mazzeo Rinaldi, F., Mendes, I., Paruccini, M., 1998. A decision support system for urban waste management. European Journal of Operational Research 109, 2, 330-341.

Halim, A.H., Ismail, I., 2019. Combinatorial optimization: comparison of heuristic algorithms in travelling salesman problem. Archives of Computational Methods in Engineering 26, 2, 367-380.

Han, K.-H., Kim, J.-H., 2002. Quantum-inspired evolutionary algorithm for a class of combinatorial optimization. IEEE Transactions on Evolutionary Computation 6, 6, 580-593.

Hartmann, S., Briskorn, D., 2010. A survey of variants and extensions of the resource-constrained project scheduling problem. European Journal of Operational Research 207, 1, 1-14.

Hertz, A., Widmer, M., 2003. Guidelines for the use of meta-heuristics in combinatorial optimization. European Journal of Operational Research 151, 2, 247-252.

Hespe, D., Lamm, S., Schulz, C., Strash, D., 2020. WeGotYouCovered: the winning solver from the PACE 2019 Challenge, vertex cover track. In Bücker, H. M., Li, X. S., (eds) 2020 Proceedings of the SIAM Workshop on Combinatorial Scientific Computing, Philadelphia, PA. Society for Industrial and Applied Mathematics, Philadelphia, PA, pp. 1-11.

Hirsch, J.E., 2005. An index to quantify an individual's scientific research output. Proceedings of the National Academy of Sciences of the United States of America 102, 46, 16569-16572.

Hoffman, K.L., Padberg, M., Rinaldi, G., 2013. Traveling salesman problem. In Encyclopedia of Operations Research and Management Science, Vol. 1, Springer US, New York, pp. 1573-1578.

Hooker, J.N., 1995. Testing heuristics: we have it all wrong. Journal of Heuristics 1, 1, 33-42.

Hopfield, J.J., Tank, D.W., 1985. "Neural” computation of decisions in optimization problems. Biological Cybernetics 52, $3,141-152$.

Hosseini, H.S., 2009. The intelligent water drops algorithm: a nature-inspired swarm-based optimization algorithm. International Journal of Bio-Inspired Computation 1, 1/2, 71.

Ibaraki, T., 1976. Integer programming formulation of combinatorial optimization problems. Discrete Mathematics 16, 1, 39-52.

Jaqaman, K., Loerke, D., Mettlen, M., Kuwata, H., Grinstein, S., Schmid, S.L., Danuser, G., 2008. Robust single-particle tracking in live-cell time-lapse sequences. Nature Methods 5, 8, 695-702.

Johnson, M.W., Amin, M.H.S., Gildert, S., Lanting, T., Hamze, F., Dickson, N., Harris, R., Berkley, A.J., Johansson, J., Bunyk, P., Chapple, E.M., Enderud, C., Hilton, J.P., Karimi, K., Ladizinsky, E., Ladizinsky, N., Oh, T., Perminov, I., Rich, C., Thom, M.C., Tolkacheva, E., Truncik, C.J.S., Uchaikin, S., Wang, J., Wilson, B., Rose, G., 2011. Quantum annealing with manufactured spins. Nature 473, 7346, 194-198.

Jozefowiez, N., Semet, F., Talbi, E.-G., 2008. Multi-objective vehicle routing problems. European Journal of Operational Research 189, 2, 293-309.

Kendall, G., Bai, R., Błazewicz, J., de Causmaecker, P., Gendreau, M., John, R., Li, J., McCollum, B., Pesch, E., Qu, R., Sabar, N., Berghe, G.V., Yee, A., 2016. Good laboratory practice for optimization research. Journal of the Operational Research Society 67, 4, 676-689. 
Kheiri, A., Dragomir, A.G., Mueller, D., Gromicho, J., Jagtenberg, C., van Hoorn, J.J., 2019. Tackling a VRP challenge to redistribute scarce equipment within time windows using metaheuristic algorithms. EURO Journal on Transportation and Logistics 8, 5, 561-595.

Kirkpatrick, S., Gelatt, C.D., Vecchi, M.P., 1983. Optimization by simulated annealing. Science (New York, N. Y.) 220, 4598, 671-680.

Knill, E., Laflamme, R., Milburn, G.J., 2001. A scheme for efficient quantum computation with linear optics. Nature 409, 6816, 46-52.

Lanza, G., Ferdows, K., Kara, S., Mourtzis, D., Schuh, G., Váncza, J., Wang, L., Wiendahl, H.-P., 2019. Global production networks: design and operation. CIRP Annals 68, 2, 823-841.

Levenshtein, V.I., 1966. Binary codes capable of correcting deletions, insertions, and reversals. Cybernetics and Control Theory 10, 8, 707-710.

Li, C.-M., Fang, Z., Jiang, H., Xu, K., 2018. Incremental upper bound for the maximum clique problem. INFORMS Journal on Computing 30, 1, 137-153.

Loiola, E.M., Abreu, N.M.M., Boaventura-Netto, P.O., Hahn, P., Querido, T., 2007. A survey for the quadratic assignment problem. European Journal of Operational Research 176, 2, 657-690.

Martí, R., Pardalos, P. M., Resende, M. G. C. (eds), 2018. Handbook of Heuristics. Springer International Publishing, Cham.

Martínez-Álvarez, F., Asencio-Cortés, G., Torres, J.F., Gutiérrez-Avilés, D., Melgar-García, L., Pérez-Chacón, R., RubioEscudero, C., Riquelme, J.C., Troncoso, A., 2020. Coronavirus optimization algorithm: a bioinspired metaheuristic based on the COVID-19 propagation model. Available at https://arxiv.org/pdf/2003.13633 (accessed 19 July 2020).

Mavromatidis, G., Orehounig, K., Carmeliet, J., 2018. A review of uncertainty characterisation approaches for the optimal design of distributed energy systems. Renewable and Sustainable Energy Reviews 88, 258-277.

Meskina, S.B., Doggaz, N., Khalgui, M., Li, Z., 2018. Reconfiguration-based methodology for improving recovery performance of faults in smart grids. Information Sciences, 454-455, 73-95.

Mladenović, N., Hansen, P., 1997. Variable neighborhood search. Computers \& Operations Research 24, 11, 1097-1100.

Mohammadi Bidhandi, H., Yusuff, Mohd.R., Megat Ahmad, M.M.H., Abu Bakar, M.R., 2009. Development of a new approach for deterministic supply chain network design. European Journal of Operational Research 198, 1, $121-128$.

Mundi, I., Alemany, M.M.E., Poler, R., Fuertes-Miquel, V.S., 2019. Review of mathematical models for production planning under uncertainty due to lack of homogeneity: proposal of a conceptual model. International Journal of Production Research 57, 15-16, 5239-5283.

Nagy, G., Salhi, S., 2007. Location-routing: issues, models and methods. European Journal of Operational Research 177, 2, 649-672.

Nouiri, M., Bekrar, A., Jemai, A., Niar, S., Ammari, A.C., 2018. An effective and distributed particle swarm optimization algorithm for flexible job-shop scheduling problem. Journal of Intelligent Manufacturing 29, 3, 603-615.

Pardalos, P M., Du, D-Z; Graham, R L. (eds), 2013. Handbook of Combinatorial Optimization. Springer, New York.

Pessoa, A., Sadykov, R., Uchoa, E., Vanderbeck, F., 2020. A generic exact solver for vehicle routing and related problems. Mathematical Programming 183, 1-2, 483-523.

Pillac, V., Gendreau, M., Guéret, C., Medaglia, A.L., 2013. A review of dynamic vehicle routing problems. European Journal of Operational Research 225, 1, 1-11.

Pop, P.C., 2020. The generalized minimum spanning tree problem: an overview of formulations, solution procedures and latest advances. European Journal of Operational Research 283, 1, 1-15.

Prodhon, C., Prins, C., 2014. A survey of recent research on location-routing problems. European Journal of Operational Research 238, 1, 1-17.

Rahmaniani, R., Crainic, T.G., Gendreau, M., Rei, W., 2017. The Benders decomposition algorithm: a literature review. European Journal of Operational Research 259, 3, 801-817.

Razmjooy, N., Khalilpour, M., Ramezani, M., 2016. A new meta-heuristic optimization algorithm inspired by FIFA World Cup competitions: theory and its application in PID designing for AVR system. Journal of Control, Automation and Electrical Systems 27, 4, 419-440.

San Segundo, P., Lopez, A., Pardalos, P.M., 2016. A new exact maximum clique algorithm for large and massive sparse graphs. Computers \& Operations Research 66, 81-94.

(C) 2021 The Authors.

International Transactions in Operational Research published by John Wiley \& Sons Ltd on behalf of International Federation of Operational Research Societies 
Santini, A., Ropke, S., Hvattum, L.M., 2018. A comparison of acceptance criteria for the adaptive large neighbourhood search metaheuristic. Journal of Heuristics 24, 5, 783-815.

Schmidt, M., Schöbel, A., Thom, L., 2019. Min-ordering and max-ordering scalarization methods for multi-objective robust optimization. European Journal of Operational Research 275, 2, 446-459.

Shishvan, M.S., Sattarvand, J., 2015. Long term production planning of open pit mines by ant colony optimization. European Journal of Operational Research 240, 3, 825-836.

Silver, D., Huang, A., Maddison, C.J., Guez, A., Sifre, L., van den Driessche, G., Schrittwieser, J., Antonoglou, I., Panneershelvam, V., Lanctot, M., Dieleman, S., Grewe, D., Nham, J., Kalchbrenner, N., Sutskever, I., Lillicrap, T., Leach, M., Kavukcuoglu, K., Graepel, T., Hassabis, D., 2016. Mastering the game of go with deep neural networks and tree search. Nature 529, 7587, $484-489$.

Sörensen, K., 2015. Metaheuristics-the metaphor exposed. International Transactions in Operational Research 22, 1, 3-18.

Sörensen, K., Arnold, F., Palhazi Cuervo, D., 2019. A critical analysis of the "improved Clarke and Wright savings algorithm. International Transactions in Operational Research 26, 1, 54-63.

Sörensen, K., Schittekat, P., 2013. Statistical analysis of distance-based path relinking for the capacitated vehicle routing problem. Computers \& Operations Research 40, 12, 3197-3205.

Sörensen, K., Sevaux, M., Glover, F., 2018. A history of metaheuristics. In Martí, R., Pardalos, P. M., Resende, M. G. C. (eds) Handbook of Heuristics, Springer International Publishing, Cham, pp. 791-808.

Spiliopoulos, K., Sofianopoulou, S., 2007. Calculating distances for dissimilar strings: the shortest path formulation revisited. European Journal of Operational Research 177, 1, 525-539.

Stützle, T., Hoos, H.H., 2000. MAX-MIN ant system. Future Generation Computer Systems 16, 8, 889-914.

Swan, J., Adriaenson, S., Brownlee, A.E.I., Johnson, C.G., Kheiri, A., Krawiec, F., Merelo, J.J., Minku, L.L., Özcan, E., Pappa, G.L., Garcia-Sanchez, P., Sörensen, K., Voß, S., Wagner, M., White, D.R., 2020. Towards Metaheuristics "in the Large". Available at https://arxiv.org/abs/2011.09821 (accessed 30 November 2020).

Taillard, E., 1993. Benchmarks for basic scheduling problems. European Journal of Operational Research 64, 2, $278-285$.

Talbi, E.-G., 2016. Combining metaheuristics with mathematical programming, constraint programming and machine learning. Annals of Operations Research 240, 1, 171-215.

Tero, A., Takagi, S., Saigusa, T., Ito, K., Bebber, D.P., Fricker, M.D., Yumiki, K., Kobayashi, R., Nakagaki, T., 2010. Rules for biologically inspired adaptive network design. Science (New York, N. Y.) 327, 5964, 439-442.

UNESCO (2020) Science,technology and innovation: Gross domestic expenditure on R\&D (GERD), GERD as a percentage of GDP, GERD per capita and GERD per researcher. Available at http://data.uis.unesco.org/Index.aspx? DataSetCode=SCN_DS\&lang=en (accessed 22 April 2020).

van den Bergh, J., Beliën, J., Bruecker, P., Demeulemeester, E., Boeck, L. (2013. Personnel scheduling: a literature review. European Journal of Operational Research 226, 3, 367-385.

Walteros, J.L., Buchanan, A., 2020. Why is maximum clique often easy in practice? Operations Research 68, 6, 1866-1895.

Watson, J.-P., Beck, J.C., Howe, A.E., Whitley, L.D., 2003. Problem difficulty for tabu search in job-shop scheduling. Artificial Intelligence 143, 2, 189-217.

Weinand, J.M., 2020. Reviewing municipal energy system planning in a bibliometric analysis: evolution of the research field between 1991 and 2019. Energies 13, 6, 1367.

Weinand, J.M., Kleinebrahm, M., McKenna, R., Mainzer, K., Fichtner, W., 2019. Developing a combinatorial optimisation approach to design district heating networks based on deep geothermal energy. Applied Energy 251, 113367.

Wen, L., Zhou, K., Yang, S., Li, L., 2018. Compression of smart meter big data: a survey. Renewable and Sustainable Energy Reviews 91, 59-69.

Wen, Z., Yin, W., 2013. A feasible method for optimization with orthogonality constraints. Mathematical Programming $142,1-2,397-434$.

Weyland, D., 2010. A rigorous analysis of the harmony search algorithm. International Journal of Applied Metaheuristic Computing 1, 2, 50-60.

Weyland, D., 2015. A critical analysis of the harmony search algorithm — how not to solve Sudoku. Operations Research Perspectives 2, 97-105.

Williamson, D.P., Shmoys, D.B., 2011. The Design of Approximation Algorithms. Cambridge University Press, Cambridge. 
Xia, Z., Xu, Z., Chen, M., Liu, Q., 2016. Recent developments in the new inorganic solid-state LED phosphors. Dalton Transactions 45, 28, 11214-11232.

Xiao, L., Boyd, S., 2004. Fast linear iterations for distributed averaging. Systems \& Control Letters 53, 1, 65-78.

$\mathrm{Xu}$, L., Jiang, C., Wang, J., Yuan, J., Ren, Y., 2014. Information security in big data: privacy and data mining. IEEE Access 2, 1149-1176.

Xu, P., Gu, Q., Wang, W., Wong, L., Bower, A.G.W., Collins, C.H., Koffas, M.A.G., 2013. Modular optimization of multi-gene pathways for fatty acids production in E. coli. Nature communications 4, 1409.

Yao, X., Liu, Y., Lin, G., 1999. Evolutionary programming made faster. IEEE Transactions on Evolutionary Computation $3,2,82-102$.

Zäpfel, G., Braune, R., Bögl, M., 2010. Summarizing remarks on metaheuristics. In Zäpfel, G., Bögl, M., Braune, R. (eds) Metaheuristic Search Concepts: A Tutorial with Applications to Production and Logistics, Springer, Berlin, pp. $145-155$.

Zhang, C., Zhou, K., Yang, S., Shao, Z., 2017. On electricity consumption and economic growth in China. Renewable and Sustainable Energy Reviews 76, 353-368.

Zhou, N.-F., Kjellerstrand, H., Fruhman, J., 2015. Constraint Solving and Planning with Picat. Springer, Cham.

\section{Appendix}

\section{A.1. Publication distribution and collaboration of authors}

Table A1 shows the top 20 of the most productive authors in the field of CO, with Panos M. Pardalos (50 publications), Gerhard J. Woeginger (46), and Fred Glover (40) at the top. The trend in the number of publications is particularly upward for F. Glover, J.K. Hao, K. Aihara, N. Mladenovic,

Table A1

The top 20 of the most productive authors in terms of publications on combinatorial optimization

\begin{tabular}{|c|c|c|c|c|c|}
\hline Author & Total publications & Trend & h-Index & g-Index & m-Index \\
\hline P.M. Pardalos & 50 & $\uparrow$ & 15 & 26 & 0.60 \\
\hline G.J. Woeginger & 46 & $\nearrow$ & 13 & 21 & 0.48 \\
\hline F. Glover & 40 & $\uparrow \uparrow \uparrow$ & 19 & 33 & 0.68 \\
\hline J.K. Hao & 37 & $\uparrow \uparrow \uparrow$ & 16 & 30 & 0.67 \\
\hline M.G.C. Resende & 36 & $\uparrow$ & 20 & 36 & 0.77 \\
\hline M. Hifi & 27 & $\uparrow$ & 14 & 22 & 0.58 \\
\hline K. Aihara & 25 & $\uparrow \uparrow \uparrow$ & 14 & 25 & 0.54 \\
\hline X. Yao & 24 & $\uparrow$ & 12 & 24 & 0.41 \\
\hline S.M. Sait & 23 & $\uparrow \uparrow$ & 5 & 13 & 0.19 \\
\hline V.G. Deineko & 22 & $\nearrow$ & 8 & 12 & 0.32 \\
\hline N. Mladenovic & 22 & $\uparrow \uparrow \uparrow$ & 15 & 22 & 0.63 \\
\hline C.C. Ribeiro & 22 & $\uparrow$ & 16 & 22 & 0.67 \\
\hline T. Stützle & 22 & $\uparrow \uparrow$ & 16 & 22 & 0.70 \\
\hline A.N. Letchford & 21 & $\uparrow \uparrow$ & 9 & 14 & 0.45 \\
\hline S. Onn & 20 & $\uparrow$ & 8 & 13 & 0.30 \\
\hline W. J. Gutjahr & 19 & $\uparrow \uparrow$ & 15 & 19 & 0.71 \\
\hline A. Kasperski & 19 & $\uparrow$ & 10 & 16 & 0.67 \\
\hline P.F. Stadler & 19 & $\uparrow \uparrow \uparrow$ & 10 & 19 & 0.34 \\
\hline Z. Tang & 19 & $\uparrow \uparrow$ & 6 & 7 & 0.33 \\
\hline C. Blum & 18 & $\uparrow \uparrow$ & 10 & 18 & 0.56 \\
\hline
\end{tabular}

(C) 2021 The Authors.

International Transactions in Operational Research published by John Wiley \& Sons Ltd on behalf of International Federation of Operational Research Societies 


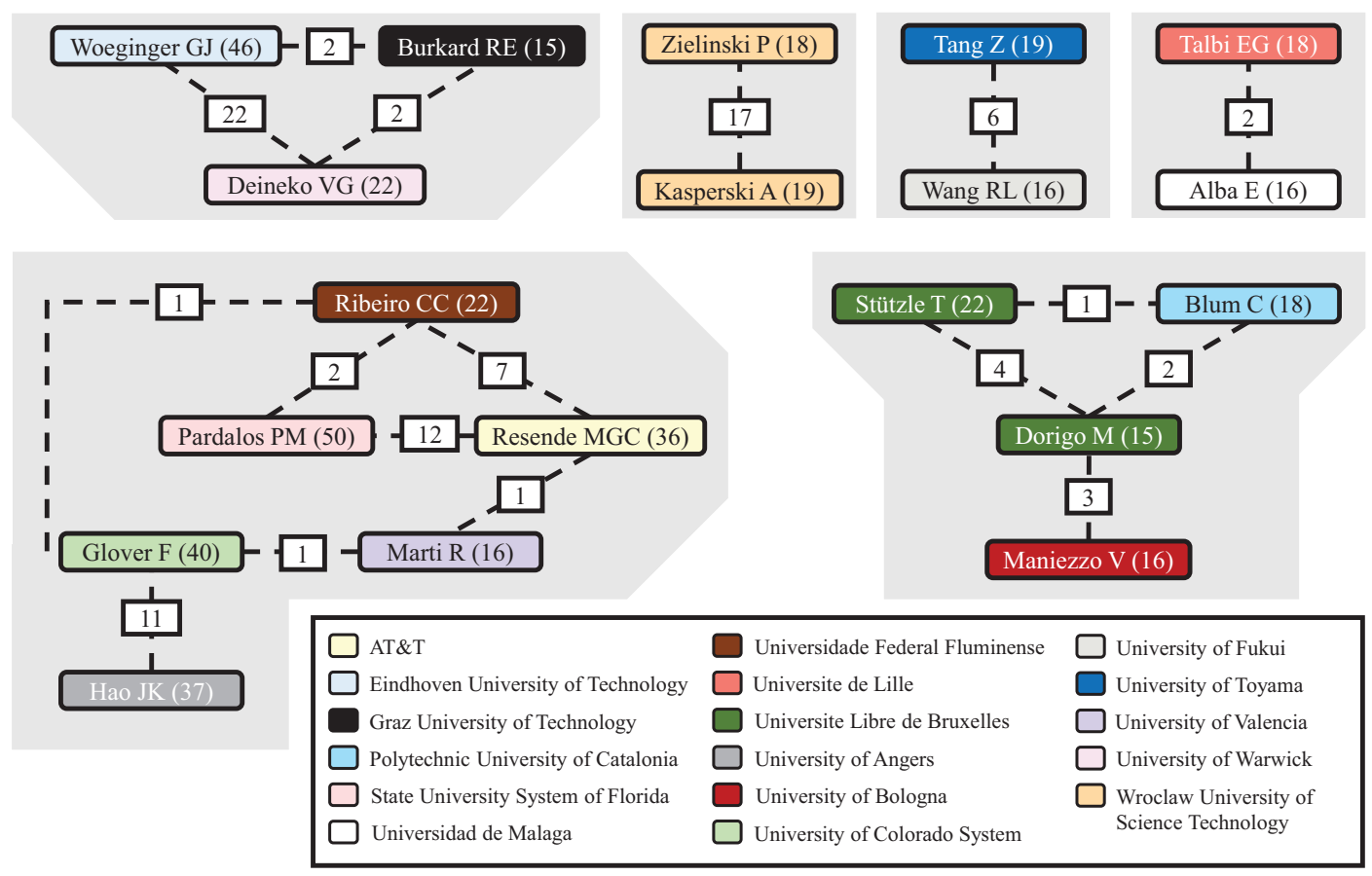

Fig. A1. Collaborations network of authors with at least 15 publications and at least one collaboration among these authors. In parentheses behind the authors is the total number of publications on CO, and in the boxes on the edges refer to the number of collaborations. The colors show the affiliation of the authors during the majority of their publications.

and P.F. Stadler. Interestingly, the fifth-ranked Mauricio G.C. Resende has the highest $h$-index, $g$ index, and $m$-index among the top 20, which means that his articles are cited a lot, that his most cited articles have very high citation rates, and that his articles are most cited in relation to the year of publication of the first article. Figure A1, which shows the collaborations of the top authors, also shows in which organizations the top authors have published most of their articles. It is evident that these authors are collaborating in the field of $\mathrm{CO}$, albeit to a small extent. Most collaborations (22) took place between Gerhard J. Woeginger and Vladimir Deineko.

\section{A.2. Most frequently cited articles}

Please see Table A2.

\section{A.3. Most important topics of countries, organizations, and sources}

Table A3 shows the most common and therefore probably most important subject of each of the top five most relevant countries, organizations, and sources. These topics overlap almost entirely with the most relevant topics in all 8393 articles. Nevertheless, trends can be deduced for certain topics. In the CO publications from the United States and Germany, for example, the keyword approximation algorithm appears most frequently (in 5\% of the publications in each case), while in 


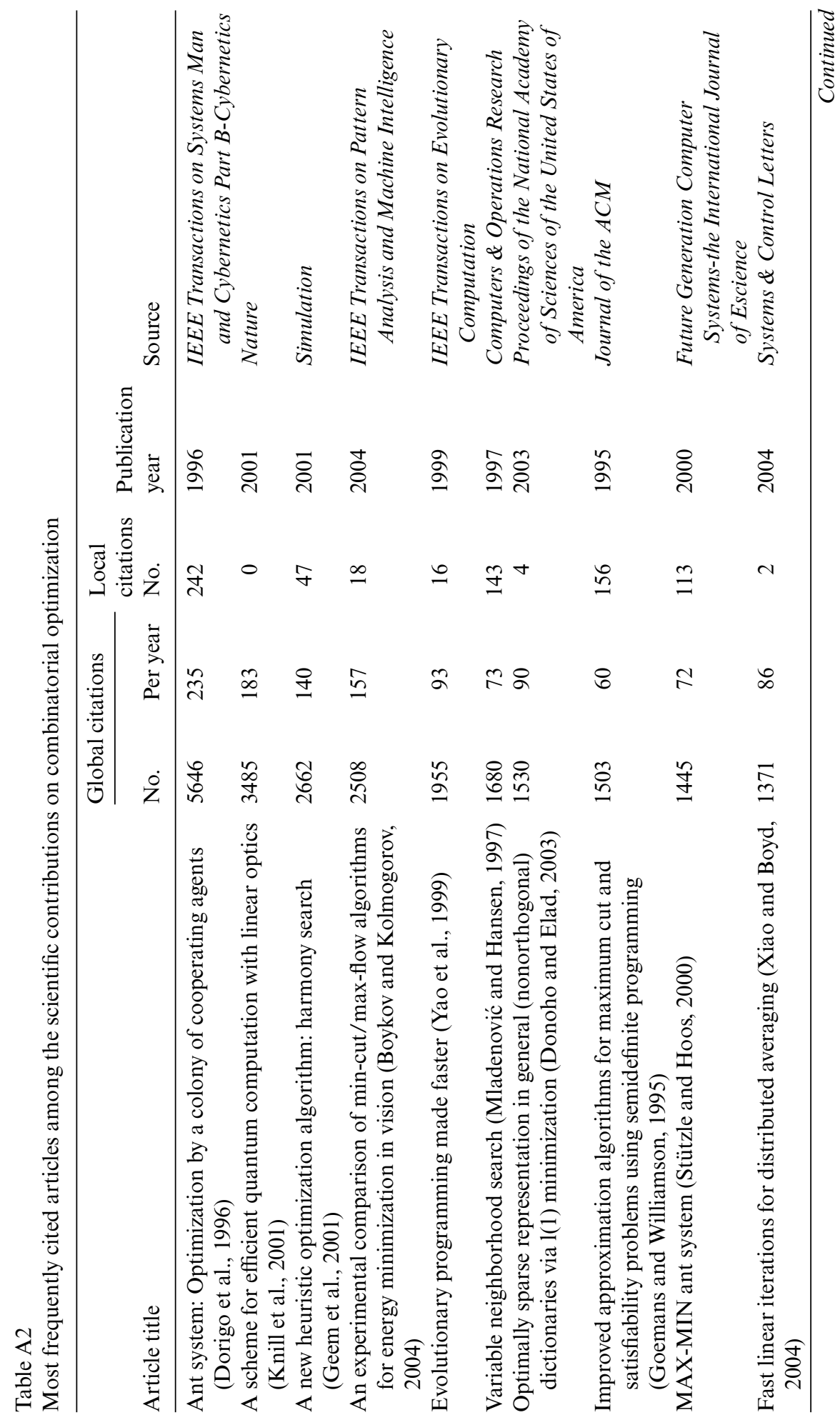

(C) 2021 The Authors.

International Transactions in Operational Research published by John Wiley \& Sons Ltd on behalf of International Federation of Operational Research Societies 
J.M. Weinand et al. / Intl. Trans. in Op. Res. 0 (2021) 1-39

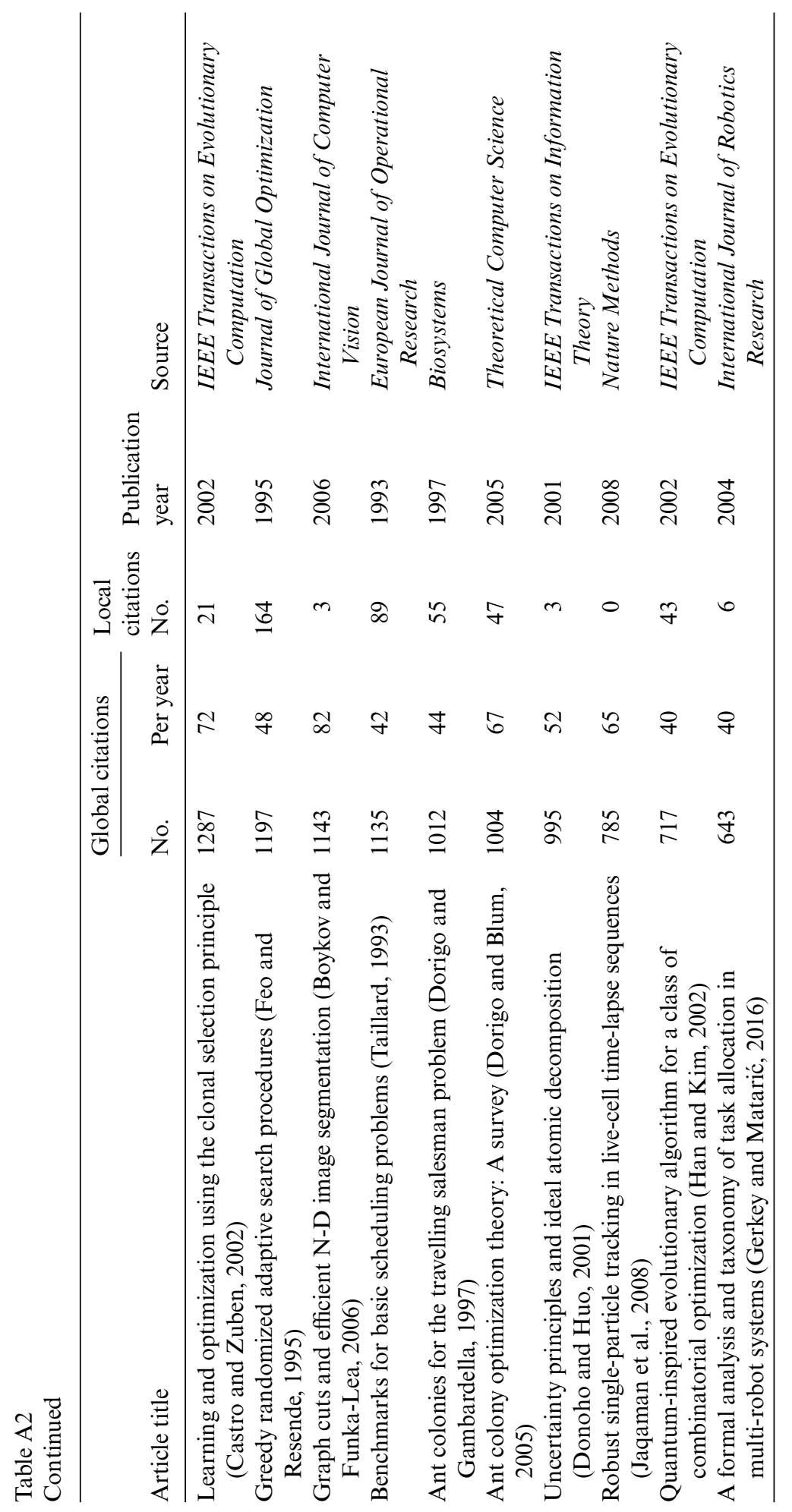

(C) 2021 The Authors. International Transactions in Operational Research published by John Wiley \& Sons Ltd on behalf of International Federation of Operational Research Societies 
Table A3

Most important topics in publications on combinatorial optimization in the top five relevant countries, organizations, and sources

\begin{tabular}{|c|c|c|c|}
\hline \multirow{2}{*}{$\begin{array}{l}\text { Country, organization, or } \\
\text { source }\end{array}$} & \multirow[b]{2}{*}{ Main topics } & \multicolumn{2}{|c|}{$\begin{array}{l}\text { Number of } \\
\text { publications }\end{array}$} \\
\hline & & No. & $\%$ \\
\hline \multirow[t]{3}{*}{ United States } & Approximation algorithms & 104 & 5 \\
\hline & Heuristics & 97 & 5 \\
\hline & Genetic algorithms & 81 & 4 \\
\hline \multirow[t]{3}{*}{ China } & Genetic algorithms & 84 & 7 \\
\hline & Ant colony optimization & 47 & 4 \\
\hline & Local search & 43 & 4 \\
\hline \multirow[t]{3}{*}{ France } & Metaheuristics & 52 & 8 \\
\hline & Heuristics & 45 & 7 \\
\hline & Branch and bound & 34 & 5 \\
\hline \multirow[t]{3}{*}{ Germany } & Approximation algorithms & 29 & 5 \\
\hline & Integer programming & 20 & 3 \\
\hline & Simulated annealing & 17 & 3 \\
\hline \multirow[t]{3}{*}{ Japan } & Genetic algorithms & 57 & 10 \\
\hline & Neural network & 37 & 7 \\
\hline & Traveling salesman problem & 23 & 4 \\
\hline \multirow{3}{*}{$\begin{array}{l}\text { French National Centre for } \\
\text { Scientific Research (CNRS) }\end{array}$} & Metaheuristics & 18 & 7 \\
\hline & Dynamic programming & 17 & 7 \\
\hline & Scheduling & 16 & 6 \\
\hline \multirow{3}{*}{$\begin{array}{l}\text { University of California } \\
\text { System }\end{array}$} & Approximation algorithms & 12 & 7 \\
\hline & Algorithms & 10 & 6 \\
\hline & Dynamic programming & 6 & 4 \\
\hline \multirow[t]{3}{*}{ Chinese Academy of Sciences } & Local search & 7 & 6 \\
\hline & Inverse problem & 4 & 3 \\
\hline & Evolutionary algorithms & 4 & 3 \\
\hline \multirow{3}{*}{$\begin{array}{l}\text { National Institute for Research } \\
\text { in Digital Science and } \\
\text { Technology (INRIA) }\end{array}$} & Branch and bound & 11 & 10 \\
\hline & Multiobjective optimization & 8 & 7 \\
\hline & Integer programming/metaheuristics & 7 & 6 \\
\hline \multirow{2}{*}{$\begin{array}{l}\text { Massachusetts Institute of } \\
\text { Technology (MIT) }\end{array}$} & Approximation algorithms & 13 & 13 \\
\hline & $\begin{array}{l}\text { Heuristics/semidefinite } \\
\text { programming/randomized } \\
\text { algorithms }\end{array}$ & 4 & 4 \\
\hline \multirow{3}{*}{$\begin{array}{l}\text { European Journal of } \\
\text { Operational Research }\end{array}$} & Heuristics & 93 & 15 \\
\hline & Metaheuristics & 72 & 12 \\
\hline & Integer programming & 64 & 10 \\
\hline \multirow{3}{*}{$\begin{array}{l}\text { Lecture Notes in Computer } \\
\text { Science }\end{array}$} & Ant colony optimization/simulated & 6 & 2 \\
\hline & annealing & 4 & 1 \\
\hline & $\begin{array}{l}\text { Linear programming/approximation } \\
\text { algorithms }\end{array}$ & & \\
\hline Computers \& Operations & Metaheuristics & 35 & 11 \\
\hline \multirow[t]{2}{*}{ Research } & Genetic algorithms & 34 & 11 \\
\hline & Heuristics & 21 & 7 \\
\hline \multirow[t]{3}{*}{ Discrete Applied Mathematics } & Approximation algorithms & 13 & 8 \\
\hline & Integer programming & 9 & 6 \\
\hline & Computational complexity & 7 & 4 \\
\hline
\end{tabular}

(C) 2021 The Authors.

International Transactions in Operational Research published by John Wiley \& Sons Ltd on behalf of International Federation of Operational Research Societies 
Table A3

Continued

\begin{tabular}{llrr}
\hline Country, organization, or & & \multicolumn{2}{c}{$\begin{array}{c}\text { Number of } \\
\text { publications }\end{array}$} \\
\cline { 2 - 4 } source & Main topics & No. & $\%$ \\
\hline Annals of Operations Research & Metaheuristics & 16 & 13 \\
& Heuristics/integer programming & 12 & 8 \\
\hline
\end{tabular}

Note: The percentage values refer to the total number of publications of the respective country, organization or source.

China and Japan genetic algorithms are most relevant ( $7 \%$ and $10 \%$, respectively). Japanese authors also seem to be among the pioneers in the field of neural networks in $\mathrm{CO}$, as they are involved in $33 \%$ of these studies. The research of the institutes logically shows similar tendencies as the research of their countries. It is also interesting to note that for the most relevant source EJOR a clear trend toward heuristics and metaheuristics can be seen (with at least $12 \%$ of the publications each) while the keywords in the second most relevant source Lecture Notes in Computer Science show no clear trend.

\section{A.4. Single-word analysis}

Table A4

The most relevant "single keywords" in publications on combinatorial optimisation divided into categories

\begin{tabular}{|c|c|c|c|c|c|}
\hline \multirow[b]{2}{*}{ Single word } & \multicolumn{2}{|c|}{ Appearances } & \multirow{2}{*}{$\begin{array}{l}\text { Mean } \\
\text { year }\end{array}$} & \multirow[b]{2}{*}{ Two most relevant keywords } & \multirow[b]{2}{*}{ Two most relevant journals } \\
\hline & No. & $\%$ & & & \\
\hline Optimization & 5239 & 62 & 2009.7 & & \\
\hline Combinatorial & 3654 & 44 & 2009.3 & & \\
\hline Algorithms & 2437 & 29 & 2009.9 & & \\
\hline Problem & 2318 & 28 & 2009.8 & & \\
\hline Programming & 1186 & 14 & 2009.6 & & \\
\hline Search & 1133 & 13 & 2009.5 & & \\
\hline Network & 1009 & 12 & 2008.4 & & \\
\hline Scheduling & 736 & 9 & 2009.9 & & \\
\hline Genetic & 683 & 8 & 2008.9 & & \\
\hline Heuristic & 674 & 8 & 2009.1 & & \\
\hline Graph & 600 & 7 & 2009.3 & & \\
\hline System & 557 & 7 & 2009.3 & & \\
\hline Metaheuristic & 542 & 6 & 2010.7 & & \\
\hline And & 470 & 6 & 2009.7 & & \\
\hline Design & 441 & 5 & 2009.4 & & \\
\hline Annealing & 426 & 5 & 2006.3 & & \\
\hline Integer & 422 & 5 & 2010.1 & & \\
\hline Assignment & 411 & 5 & 2008.8 & & \\
\hline
\end{tabular}

Continued 
Table A4

Continued

\begin{tabular}{|c|c|c|c|c|c|}
\hline \multirow[b]{2}{*}{ Single word } & \multicolumn{2}{|c|}{ Appearances } & \multirow{2}{*}{$\begin{array}{l}\text { Mean } \\
\text { year }\end{array}$} & \multirow[b]{2}{*}{ Two most relevant keywords } & \multirow[b]{2}{*}{ Two most relevant journals } \\
\hline & No. & $\%$ & & & \\
\hline Local & 409 & 5 & 2010.2 & & \\
\hline Analysis & 395 & 5 & 2009.9 & & \\
\hline Approximation & 388 & 5 & 2009.4 & & \\
\hline Traveling & 384 & 5 & 2008.6 & & \\
\hline Simulated & 379 & 5 & 2006.2 & & \\
\hline Methods & 376 & 4 & 2008.9 & & \\
\hline Computational & 364 & 4 & 2010.0 & & \\
\hline Constrained & 364 & 4 & 2009.9 & & \\
\hline Evolutionary & 353 & 4 & 2010.7 & & \\
\hline Multiobjective & 351 & 4 & 2010.9 & & \\
\hline Salesman & 349 & 4 & 2008.2 & & \\
\hline Of & 344 & 4 & 2009.8 & & \\
\hline Routing & 318 & 4 & 2010.2 & & \\
\hline Linear & 316 & 4 & 2009.8 & & \\
\hline Ant & 307 & 4 & 2010.1 & & \\
\hline Colony & 307 & 4 & 2010.6 & & \\
\hline Tabu & 304 & 4 & 2007.5 & & \\
\hline Quadratic & 276 & 3 & 2009.7 & & \\
\hline Model & 276 & 3 & 2011.2 & & \\
\hline Parallel & 275 & 3 & 2007.5 & & \\
\hline Dynamic & 274 & 3 & 2010.1 & & \\
\hline Neural & 273 & 3 & 2004.7 & & \\
\hline Functional & 256 & 3 & 2009.5 & & \\
\hline Set & 249 & 3 & 2009.1 & & \\
\hline Planning & 247 & 3 & 2010.5 & & \\
\hline Evolution & 245 & 3 & 2011.5 & & \\
\hline Theory & 244 & 3 & 2008.8 & & \\
\hline Knapsack & 241 & 3 & 2010.2 & & \\
\hline Complexity & 238 & 3 & 2009.2 & & \\
\hline Vehicle & 228 & 3 & 2010.5 & & \\
\hline Selective & 215 & 3 & 2011.2 & & \\
\hline Swarm & 209 & 2 & 2010.7 & & \\
\hline Computing & 207 & 2 & 2010.5 & & \\
\hline Production & 202 & 2 & 2011.1 & $\begin{array}{l}\text { Genetic algorithm (23) and } \\
\text { production planning }(8)\end{array}$ & $\begin{array}{l}\text { European Journal of Operational } \\
\text { Research (19) and International } \\
\text { Journal of Production Research (10) }\end{array}$ \\
\hline Relaxation & 200 & 2 & 2008.5 & & \\
\hline Optimal & 198 & 2 & 2010.1 & & \\
\hline Minimum & 198 & 2 & 2010.6 & & \\
\hline Data & 191 & 2 & 2011.4 & $\begin{array}{l}\text { Data mining (31) and } \\
\text { heuristics (12) }\end{array}$ & $\begin{array}{l}\text { European Journal of Operational } \\
\text { Research (14) and Computers \& } \\
\text { Operations Research (11) }\end{array}$ \\
\hline Neighborhood & 189 & 2 & 2010.8 & & \\
\hline Learning & 189 & 2 & 2011.6 & & \\
\hline
\end{tabular}


Table A4

Continued

\begin{tabular}{|c|c|c|c|c|c|}
\hline \multirow[b]{2}{*}{ Single word } & \multicolumn{2}{|c|}{ Appearances } & \multirow{2}{*}{$\begin{array}{l}\text { Mean } \\
\text { year }\end{array}$} & \multirow[b]{2}{*}{ Two most relevant keywords } & \multirow[b]{2}{*}{ Two most relevant journals } \\
\hline & No. & $\%$ & & & \\
\hline Maximum & 187 & 2 & 2009.1 & & \\
\hline Stochastic & 184 & 2 & 2009.7 & & \\
\hline Tree & 184 & 2 & 2009.7 & & \\
\hline Bound & 183 & 2 & 2009.1 & & \\
\hline Allocation & 180 & 2 & 2010.4 & & \\
\hline Flow & 172 & 2 & 2008.6 & & \\
\hline Power & 172 & 2 & 2009.3 & $\begin{array}{l}\text { Genetic algorithm (11) and } \\
\text { smart grid (6) }\end{array}$ & $\begin{array}{l}\text { International Journal of Electrical } \\
\text { Power \& Energy Systems (14) and } \\
\text { Electric Power Systems Research } \\
\text { (8) }\end{array}$ \\
\hline Structural & 170 & 2 & 2010.3 & & \\
\hline Hybrid & 168 & 2 & 2011.4 & & \\
\hline Multiple & 168 & 2 & 2010.1 & & \\
\hline Distribution & 166 & 2 & 2010.3 & & \\
\hline Machine & 165 & 2 & 2010.7 & & \\
\hline Time & 164 & 2 & 2010.0 & & \\
\hline Location & 150 & 2 & 2010.6 & & \\
\hline Semidefinite & 148 & 2 & 2008.4 & & \\
\hline Particle & 145 & 2 & 2010.5 & & \\
\hline Path & 145 & 2 & 2011.2 & & \\
\hline Matching & 144 & 2 & 2008.2 & & \\
\hline Packing & 142 & 2 & 2011.0 & & \\
\hline Binary & 141 & 2 & 2011.0 & & \\
\hline Variable & 141 & 2 & 2010.9 & & \\
\hline Decomposition & 141 & 2 & 2011.6 & & \\
\hline Branch & 135 & 2 & 2009.0 & & \\
\hline Intelligent & 135 & 2 & 2011.9 & & \\
\hline Discrete & 132 & 2 & 2010.8 & & \\
\hline Management & 130 & 2 & 2011.3 & $\begin{array}{l}\text { Genetic algorithm (15) and } \\
\text { supply chain management } \\
(10)\end{array}$ & $\begin{array}{l}\text { European Journal of Operational } \\
\text { Research }(15) \text { and Computers \& } \\
\text { Operations Research }(7)\end{array}$ \\
\hline Spanning & 129 & 2 & 2010.1 & & \\
\hline Decision & 125 & 1 & 2010.1 & $\begin{array}{l}\text { Decision support system (17) } \\
\text { and decision making (17) }\end{array}$ & $\begin{array}{l}\text { European Journal of Operational } \\
\text { Research (16) and Computers \& } \\
\text { Operations Research (6) }\end{array}$ \\
\hline Control & 125 & 1 & 2011.2 & & \\
\hline Shop & 125 & 1 & 2010.8 & & \\
\hline Energy & 123 & 1 & 2011.7 & $\begin{array}{l}\text { Energy efficiency (14) and } \\
\text { energy consumption (12) }\end{array}$ & $\begin{array}{l}\text { Applied Ocean Research (6) and IEEE } \\
\text { Systems Journal (5) }\end{array}$ \\
\hline Assembly & 123 & 1 & 2012.1 & & \\
\hline Robust & 122 & 1 & 2013.8 & & \\
\hline Generation & 122 & 1 & 2010.1 & & \\
\hline Clustering & 118 & 1 & 2010.2 & & \\
\hline Artificial & 116 & 1 & 2011.2 & & \\
\hline
\end{tabular}

Continued

(C) 2021 The Authors. International Transactions in Operational Research published by John Wiley \& Sons Ltd on behalf of International Federation of Operational Research Societies 
Table A4

Continued

\begin{tabular}{|c|c|c|c|c|c|}
\hline \multirow[b]{2}{*}{ Single word } & \multicolumn{2}{|c|}{ Appearances } & \multirow{2}{*}{$\begin{array}{l}\text { Mean } \\
\text { year }\end{array}$} & \multirow[b]{2}{*}{ Two most relevant keywords } & \multirow[b]{2}{*}{ Two most relevant journals } \\
\hline & No. & $\%$ & & & \\
\hline Lagrangian & 113 & 1 & 2007.5 & & \\
\hline Global & 112 & 1 & 2008.0 & & \\
\hline Random & 111 & 1 & 2008.4 & & \\
\hline Sequence & 110 & 1 & 2010.0 & & \\
\hline Mixed & 109 & 1 & 2011.3 & & \\
\hline Fuzzy & 107 & 1 & 2007.4 & & \\
\hline Resource & 104 & 1 & 2012.4 & & \\
\hline Strategic & 103 & 1 & 2011.6 & & \\
\hline Facility & 101 & 1 & 2010.7 & & \\
\hline Convex & 99 & 1 & 2008.8 & & \\
\hline Hopfield & 99 & 1 & 2004.5 & & \\
\hline Layout & 99 & 1 & 2008.8 & & \\
\hline Partitioning & 99 & 1 & 2008.2 & & \\
\hline Estimation & 98 & 1 & 2011.3 & & \\
\hline Modeling & 96 & 1 & 2010.6 & & \\
\hline Clique & 94 & 1 & 2011.0 & & \\
\hline Minimization & 94 & 1 & 2011.6 & & \\
\hline Adaptive & 93 & 1 & 2010.3 & & \\
\hline Matrix & 93 & 1 & 2008.8 & & \\
\hline Nonlinear & 93 & 1 & 2009.1 & & \\
\hline Information & 93 & 1 & 2010.1 & $\begin{array}{l}\text { Information theory (9) and } \\
\text { information entropy (5) }\end{array}$ & $\begin{array}{l}\text { European Journal of Operational } \\
\text { Research (2) and IEEE } \\
\text { Transactions on Wireless } \\
\text { Communications (2) }\end{array}$ \\
\hline Cooperative & 92 & 1 & 2011.0 & & \\
\hline Image & 92 & 1 & 2009.9 & $\begin{array}{l}\text { Image segmentation (19) and } \\
\text { image processing (9) }\end{array}$ & $\begin{array}{l}\text { Journal of Visual Communication and } \\
\text { Image Representation (5) and IEEE } \\
\text { Transactions on Image Processing } \\
\text { (4) }\end{array}$ \\
\hline Shortest & 92 & 1 & 2011.1 & & \\
\hline Memetic & 91 & 1 & 2012.2 & & \\
\hline Polynomial & 91 & 1 & 2006.5 & & \\
\hline Job & 91 & 1 & 2012.0 & & \\
\hline Chains & 91 & 1 & 2010.4 & & \\
\hline Polyhedral & 90 & 1 & 2007.1 & & \\
\hline Coloring & 90 & 1 & 2010.2 & & \\
\hline Transportation & 89 & 1 & 2009.6 & $\begin{array}{l}\text { Transportation }(22) \text { and } \\
\text { integer programming (10) }\end{array}$ & $\begin{array}{l}\text { European Journal of Operational } \\
\text { Research (12) and Computers \& } \\
\text { Industrial Engineering (4) }\end{array}$ \\
\hline $\begin{array}{l}\text { Branch-and- } \\
\text { bound }\end{array}$ & 88 & 1 & 2010.1 & & \\
\hline Manufacturing & 87 & 1 & 2009.8 & $\begin{array}{l}\text { Manufacturing (14) and } \\
\text { genetic algorithm (13) }\end{array}$ & $\begin{array}{l}\text { European Journal of Operational } \\
\text { Research (13) and International } \\
\text { Journal of Production Research (11) }\end{array}$ \\
\hline
\end{tabular}

(C) 2021 The Authors.

International Transactions in Operational Research published by John Wiley \& Sons Ltd on behalf of International Federation of Operational Research Societies 
Table A4

Continued

\begin{tabular}{|c|c|c|c|c|c|}
\hline \multirow[b]{2}{*}{ Single word } & \multicolumn{2}{|c|}{ Appearances } & \multirow{2}{*}{$\begin{array}{l}\text { Mean } \\
\text { year }\end{array}$} & \multirow[b]{2}{*}{ Two most relevant keywords } & \multirow[b]{2}{*}{ Two most relevant journals } \\
\hline & No. & $\%$ & & & \\
\hline Vertex & 87 & 1 & 2011.1 & & \\
\hline Cover & 87 & 1 & 2011.8 & & \\
\hline Protein & 86 & 1 & 2009.6 & $\begin{array}{l}\text { Protein design (19) and } \\
\text { protein structure } \\
\text { prediction (7) }\end{array}$ & $\begin{array}{l}\text { Journal of Computational Biology (15) } \\
\text { and Journal of Computational } \\
\text { Chemistry (11) }\end{array}$ \\
\hline Placement & 86 & 1 & 2007.4 & & \\
\hline Detection & 86 & 1 & 2011.3 & & \\
\hline Communication & 85 & 1 & 2010.4 & $\begin{array}{l}\text { Telecommunications (9) and } \\
\text { OR in } \\
\text { telecommunications (8) }\end{array}$ & $\begin{array}{l}\text { European Journal of Operational } \\
\text { Research (8) and IEEE } \\
\text { Transactions on Wireless } \\
\text { Communications (7) }\end{array}$ \\
\hline Differential & 84 & 1 & 2012.5 & & \\
\hline Cutting & 84 & 1 & 2007.3 & & \\
\hline Process & 84 & 1 & 2009.2 & & \\
\hline Uncertainty & 83 & 1 & 2013.3 & & \\
\hline Cut & 83 & 1 & 2009.6 & & \\
\hline Greedy & 83 & 1 & 2008.5 & & \\
\hline Automated & 82 & 1 & 2010.9 & & \\
\hline Matroid & 82 & 1 & 2007.2 & & \\
\hline Markov & 81 & 1 & 2007.1 & & \\
\hline Inverse & 81 & 1 & 2010.6 & & \\
\hline Balancing & 81 & 1 & 2010.8 & & \\
\hline Grasp & 80 & 1 & 2009.4 & & \\
\hline Simulation & 80 & 1 & 2009.3 & & \\
\hline Line & 80 & 1 & 2011.7 & & \\
\hline Technique & 80 & 1 & 2008.9 & & \\
\hline
\end{tabular}

Note: The words that represent specific application areas of CO (and not problems or methods as in Figure 5) are written in bold and the two most relevant keywords and journals for the articles of these application areas is shown. The percentage values refer to the total of 8393 publications. 